\title{
Zika and the Eye: Pieces of a Puzzle
}

\author{
João Rafael de Oliveira Dias ${ }^{\mathrm{a}, 2}$, Camila V. Ventura ${ }^{\mathrm{a}, \mathrm{b}, \mathrm{c}, 2}$, Bruno de Paula Freitas ${ }^{\mathrm{a}, \mathrm{d}, 2}$, \\ Juliana Prazeres ${ }^{\mathrm{a}, 2}$, Liana O. Ventura ${ }^{\mathrm{a}, \mathrm{b}, \mathrm{c}, 2}$, Vasco Bravo-Filho ${ }^{\mathrm{b}, \mathrm{c}, 2}$, Tomas Aleman ${ }^{\mathrm{e}, 2}$, \\ Albert Icksang Ko ${ }^{\mathrm{f}, g, 2}$, Andréa Zin ${ }^{\mathrm{h}, 2}$, Rubens Belfort $\mathrm{Jr}^{\mathrm{a}}{ }^{\mathrm{a}, 2}$, Mauricio Maia ${ }^{\mathrm{a}, \mathrm{i}, *, 2}$, the Zika Virus \\ Study Group ${ }^{1}$
}

a Vision Institute, Department of Ophthalmology, Paulista Medical School, Federal University of São Paulo, São Paulo, Brazil

b Altino Ventura Foundation, Recife, Pernambuco, Brazil

${ }^{\mathrm{c}}$ HOPE Eye Hospital, Recife, Pernambuco, Brazil

' Department of Ophthalmology, Roberto Santos General Hospital, Salvador, Brazil

${ }^{\mathrm{e}}$ Scheie Eye Institute at the Perelman Center for Advanced Medicine, Perelman School of Medicine, Department of Ophthalmology, University of Pennsylvania,

Philadelphia, United States

${ }^{\mathrm{f}}$ Gonçalo Moniz Research Center, Oswaldo Cruz Foundation, Salvador, Brazil

${ }^{8}$ Department of Epidemiology of Microbial Diseases, Yale School of Public Health, New Haven, CT, United States

h Clinical Research Unit, Fernandes Figueira Institute, Oswaldo Cruz Foundation, Rio de Janeiro, Brazil

${ }^{\mathrm{i}}$ Brazilian Institute of Fight Against Blindness, Assis and Presidente Prudente, São Paulo, Brazil

\begin{abstract}
A B S T R A C T
Zika virus (ZIKV) is an arbovirus mainly transmitted to humans by mosquitoes from Aedes genus. Other ways of transmission include the perinatal and sexual routes, blood transfusion, and laboratory exposure. Although the first human cases were registered in 1952 in African countries, outbreaks were only reported since 2007, when entire Pacific islands were affected. In March 2015, the first cases of ZIKV acute infection were notified in Brazil and, to date, 48 countries and territories in the Americas have confirmed local mosquito-borne transmission of ZIKV. Until 2015, ZIKV infection was thought to only cause asymptomatic or mild exanthematous febrile infections. However, after explosive ZIKV outbreaks in Polynesia and Latin American countries, it was confirmed that ZIKV could also lead to Guillain-Barré syndrome and congenital birth abnormalities. These abnormalities, which can include neurologic, ophthalmologic, audiologic, and skeletal findings, are now considered congenital Zika syndrome (CZS). Brain abnormalities in CZS include cerebral calcifications, malformations of cortical development, ventriculomegaly, lissencephaly, hypoplasia of the cerebellum and brainstem. The ocular findings, which are present in up to $70 \%$ of infants with CZS, include iris coloboma, lens subluxation, cataract, congenital glaucoma, and especially posterior segment findings. Loss of retinal pigment epithelium, the presence of a thin choroid, a perivascular choroidal inflammatory infiltrate, and atrophic changes within the optic nerve were seen in histologic analyses of eyes from deceased fetuses. To date, there is no ZIKV licensed vaccines or antiviral therapies are available for treatment. Preventive measures include individual protection from mosquito bites, control of mosquito populations and the use of barriers measures such as condoms during sexual intercourse or sexual abstinence for couples either at risk or after confirmed infection. A literature review based on studies that analyzed ocular findings in mothers and infants with CZS, with or without microcephaly, was conducted and a theoretical pathophysiologic explanation for ZIKV-ocular abnormalities was formulated.
\end{abstract}

\footnotetext{
* Corresponding author. Department of Ophthalmology, Federal University of São Paulo, Pedro de Toledo Street 781, 2nd floor, 04023-062, São Paulo, SP, Brazil.

E-mail addresses: mmaia@unifesp.br, maiamauricio@terra.com.br (M. Maia).

${ }^{1}$ All authors from the Zika Virus Study Group are listed in the Appendix.

${ }^{2}$ Percentage of work contributed by each author in the production of the manuscript is as follows: João Rafael de Oliveira Dias - 20\%; Camila V. Ventura - 10\%; Bruno de Paula Freitas -

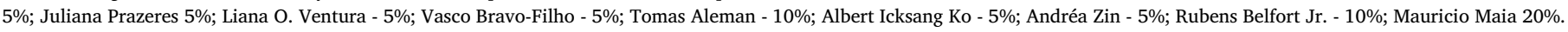




\section{Introduction}

\subsection{History of Zika virus (ZIKV)}

Zika virus (ZIKV) is a re-emerging arthropod-born virus (arbovirus) in the genus Flavivirus of the Flaviviridae family, the same family as dengue (DENV), yellow fever (YFV), Japanese encephalitis virus (JEV), and West Nile (WNV) viruses. Similarly to other flaviviruses, ZIKV is a single-strand, positive-sense RNA virus with a genome of $10,794 \mathrm{~kb}$ (Kuno and Chang, 2007). It was first identified in 1947 in a captive rhesus monkey (Macaca mulata) with pyrexia caged in the canopy of the Ziika (note original forest spelling was inadvertently changed for the virus) Forest reserve in Uganda, during the course of research into the epidemiology of yellow fever (Dick et al., 1952). One year later the virus was isolated from arboreal $A$. africanus mosquitoes at the same forest (Dick et al., 1952). The first human cases of ZIKV infection were detected in 1952 in Uganda and the United Republic of Tanzania in studies that reported the presence of neutralizing antibodies to ZIKV at blood samples (Smithburn, 1952; Macnamara, 1952). Subsequent isolations of ZIKV were made from A. africanus, A. luteocephalus and A. furficer (tree-hole bleeding mosquitoes also implicated in the sylvatic cycle of YFV) in Uganda, Senegal, Nigeria, Burkina Faso, Ivory Coast and the Central African Republic (Haddow et al., 2012).

Thereafter, serological and entomological data in the African continent indicated ZIKV infections in Uganda in 1969 and 1970 (McCrae and Kirya, 1982), Nigeria in 1971 and 1975 (Fagbami, 1979), Sierra Leone in 1972 (Robin and Mouchet, 1978), Gabon in 1975 (Jan et al., 1978), Central African Republic in 1979 (Saluzzo et al., 1981), Senegal from 1988 to 1991 (Monlun et al., 1993) and Côte d'Ivoire in 1999 (Akoua-Koffi et al., 2001).

The first direct detection of ZIKV outside Africa and the first evidence of transmission by an urban (domestic) vector were noticed when the virus was isolated from A. aegypti mosquitoes in Malaysia in 1966 (Marchette et al., 1969). In 1977 and 1978 selected patients in Klaten, Indonesia, who had recent onsets of acute fever, malaise, stomach ache, dizziness and anorexia were serologically studied and diagnosed with ZIKV infection, which is speculated that a few may have been the tip of an unrecognized outbreak (Olson et al., 1981). According to Olson et al. (1981), the onsets of illness clustered toward the end of the rainy season when populations of $A$. aegypti were most abundant in Indonesia.

By the end of the 20th century, ZIKV had been detected in India, Malaysia, the Philippines, Vietnam, Indonesia, Thailand, and Pakistan. However, despite such a wide geographic distribution, reports of human disease attributed to ZIKV infection were extremely rare until 2007 (Gatherer and Kohl, 2016). The first ZIKV outbreak described took place in April and May 2007 on the island of Yap in Federated States of Micronesia when local physicians noticed a large number of people presenting with rash, nonpurulent conjunctivitis, fever (measured or reported), arthralgia, and arthritis (Lanciotti et al., 2008; Duffy et al., 2009). Until this outbreak, no transmission of ZIKV had been reported outside of Africa and Asia (Duffy et al., 2009). Patients with suspected disease had their blood tested by reverse transcription-PCR (RT-PCR) for ZIKV and DENV during the acute phase (i.e., within 10 days after the onset of symptoms), and through antibody capture enzyme-linked immunosorbent assay (ELISA) IgM antibodies against ZIKV and DENV during the acute and the convalescent (i.e., 14 days later) phases. In this outbreak, 185 cases suspected for ZIKV disease were identified, with 49 (26\%) confirmed cases and $59(32 \%)$ probable cases. Blood samples were also obtained from 557 of the 808 eligible residents (69\%), and 414 (74\%) showed IgM antibodies against ZIKV. Fourty-three percent of the water-holding containers identified during a household survey conducted during this study were infested with mosquito larvae or pupae, and $A$. hensilli was the predominant specie, identified in $36 \%$ of the water-holding containers. The authors hypothesized that ZIKV may have been introduced to Yap by a viremic non-human primate (NHP) or through a traveler from the Philippines, as travelling between Yap and the Philippines is common (Duffy et al., 2009).

From 2007 through 2013, no new cases of human seropositivity or disease had been reported. In 2013, French Polynesia, a French overseas territory located in the South Pacific with 270,000 inhabitants at the time, experienced a large ZIKV outbreak, which began in October 2013, with an estimated 28,000 cases in February 2014 (about $11 \%$ of the population) (Cao-Lormeau et al., 2014). Serum from 584 patients was tested by RT-PCR for ZIKV and 294 samples were positive (50,3\%) (Cao-Lormeau et al., 2014). The phylogenetics tree showed that the ZIKV that emerged in French Polynesia was similar to that from Yap State 2007 and Cambodia 2010 strains, corroborating the expansion of ZIKV Asian lineage (Haddow et al., 2012; Faye et al., 2014). During the French Polynesian outbreak, the first cases of Guillain-Barré syndrome (GBS) following ZIKV infection were recorded (Oehler et al., 2014; CaoLormeau et al., 2016). A case-control study found an odds ratio for GBS of 34.1, with a wide but significant confidence interval (Cao-Lormeau et al., 2016). A retrospective study also found an unusual increase in annual congenital cerebral malformations (two-fold), brainstem dysfunction (31-fold), and severe microcephaly (14-fold) among fetuses and newborns, following the French Polynesian ZIKV epidemic (Besnard et al., 2016).

After the ZIKV outbreak in French Polynesia, outbreaks occurred in 2014 in New Caledonia (1400 confirmed cases), Cook Islands (50 confirmed and over 900 suspected cases), and Easter Island of Chile (1 confirmed and 40 suspected cases). Outbreaks also took place in Samoa (2015) and American Samoa (2016) (Roth et al., 2014; DupontRouzeyrol et al., 2015; Tognarelli et al., 2015; Pinto Junior et al., 2015; Sampathkumar and Sanchez, 2016). ZIKV was hypothesized to have been introduced to Easter Island during the annual Tapati Festival, which attracts people from other Pacific islands, including French Polynesia, where ZIKV outbreak was ongoing (Musso, 2015).

In 2015, ZIKV emerged for the first time in the Americas, initially Brazil. In 2014, Brazil hosted the Va'a World Spring Canoe Championship in Rio de Janeiro in which four Pacific countries where ZIKV had been causing outbreaks (French Polynesia, New Caledonia, the Cook Island, and Easter Island of Chile) participated. Subsequently, ZIKV may have been transferred across the country via the infected Brazilian participants and spectators who returned to their hometowns (Musso, 2015). In March 2015, the first confirmed cases of ZIKV appeared in Brazil, and phylogenetic studies suggested that ZIKV may have been introduced to Brazil during that sporting event (Musso, 2015). By December 2015, between 0.4 and 1.3 million people had been infected by the virus in Brazil, mostly in the northeastern region (Slavov et al., 2016). The potential for ZIKV emergence in Brazil was enormous because $A$. aegypti and A. albopictus were widely disseminated (Marcondes et al., 2016).

Since May 2015, ZIKV had spread to 48 countries or territories in South, Central, and North America, and the Caribbean, including Colombia, Venezuela, Dominican Republic, the US, Puerto Rico, and the US Virgin Islands (Musso and Gubler, 2016). Between January 2015 and 17 December 2017, 107 countries or territories have reported previous or current evidence of ZIKV transmission according to the European Centre for Disease Prevention and Control (ECDC, 2017a, b). The spread of ZIKV over time is summarized in Fig. 1.

\subsection{Basics of Zika infection, phylogenetics, and neurovirulence}

In April 1947, six caged rhesus monkeys were placed in the canopy of the Ziika forest in Uganda and, in April 18, the temperature of one of the caged monkeys (no. 766) was $39.7^{\circ} \mathrm{C}$. The agent isolated from monkey no. 766 was referred to as ZIKV (MR766 strain) (Dick et al., 1952). The full genome of the ZIKV MR 766 prototype strain was sequenced in its entirety in 2007 (Kuno and Chang, 2007). Later, the full sequences of the ZIKV strains from Yap State, Cambodia, Central African Republic, French Polynesia, Guatemala, Malaysia, Nigeria, Puerto Rico, Senegal, Thailand, and Brazil were sequenced (Berthet 


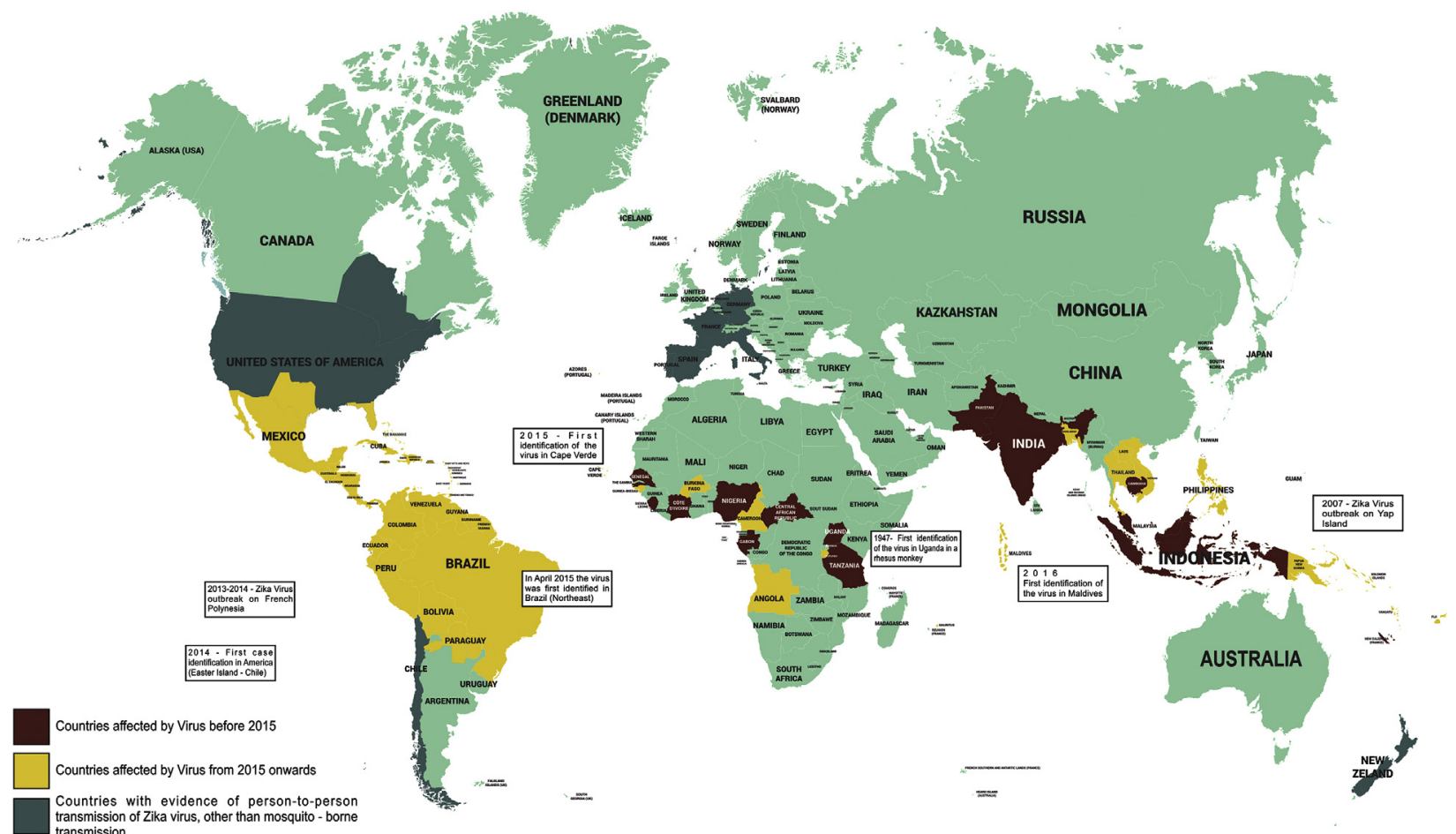

Fig. 1. The map shows the worldwide Zika virus (ZIKV) spread since 1947. Dark red indicates countries in which ZIKV cases occurred before 2015; yellow indicates countries in which ZIKV transmission occurred from 2015 onwards; and dark green indicates countries with evidence of person-to-person transmission of ZIKV, other than mosquito-borne transmission.

Sources:

1) Musso, D., Gubler, D. j. Zika Virus. 2016. Clin Microbiol Rev. 29, 487-524.

2) Faye, O., Freire, C.C.M., Iamarino, A., Faye, O., de Oliveira, J.V.C., Diallo, M., Zanotto,P.M.A., Sall, A.A. 2014. Molecular Evolution of Zika Virus during Its Emergence in the 20th Century. PLoS Negl Trop Dis. 8, e2636.

3) World Health Organization, 2017b. Zika situation report. Available at: http://www.who.int/emergencies/zika-virus/situation-report/10-march-2017/en/. Accessed on March 5, 2018.

4) Centers for Disease Control and Prevention. Zika Cases in the United States, 2018. Available at: https://www.cdc.gov/zika/reporting/case-counts.html. Accessed on March 5, 2018.

5) European Centre for Disease Prevention and Control (ECDC), 2017a. Zika transmission. Current Zika transmission. Available at: https://ecdc.europa.eu/en/ zika-virus-infection/threats-and-outbreaks/zika-transmission. (Accessed on March 31, 2018).

6) European Centre for Disease Prevention and Control (ECDC), 2017b. Zika virus transmission - List of countries: ECDC adaptation of WHO's Zika virus country classification scheme. Available at: https://ecdc.europa.eu/en/publications-data/current-zika-virus-transmission-list-countries-ecdc-adaptation-whos-zika-virus. (Accessed on March 24, 2018). Sources:

et al., 2014; Lanciotti et al., 2008, 2016).

After the ZIKV outbreak in the Yap State, Lanciotti et al. (2008) conducted the first phylogenetic study of ZIKV that identified three ZIKV lineages or subclades: East African (prototype Uganda strain), West African (Senegal strain), and Asian (ZIKV 2007 Yap strain). The Asian lineage diverged from a common ancestor that moved in Southeast Asia and the Pacific (Lanciotti et al., 2008). Based on phylogenetic studies, the current circulating ZIKV strains have evolved from the common African ancestor, MR766, representing the African lineage. A breaking point occurred with a Malaysian strain that determined that the beginning of the Asian lineage and the current ZIKV circulating in the Americas have spread from Asia (Rajah et al., 2016; Wang et al., 2016).

In the Americas, ZIKV sequences from Brazil, Colombia, Puerto Rico, and Guatemala showed more than 99\% nucleotide identity with the French Polynesian strain (Lanciotti et al., 2016; Musso and Gubler, 2016). The key question is why the outbreaks in French Polynesia and Brazil were associated with GBS and congenital Zika syndrome (CZS) cases. Data support the hypothesis that the epidemic strains of ZIKV emerged via a genetic change in the Asian lineage. The French Polynesian strain had great virulence and scientists hypothesize that this strain was introduced to Brazil in 2014 and from Brazil to other American countries. An alternate hypothesis from greater number of cases of severe disease associated with ZIKV would be related to high incidence, as GBS and CZS might only be recognized during an epidemic with numerous cases, such as those in French Polynesia and Brazil (Musso and Gubler, 2016).

Changes in the viral genome/polypeptide sequences are attributed to the emergence of highly pathogenic ZIKV strains (Morris et al., 2017). Zhu et al. (2016) noted that 25 amino acid substitutions emerged between the Malaysia 1966 pre-epidemic strain and the 2007 Yap epidemic strain. Evidence also has suggested that a combination of factors such as genetic variation in the NS5 gene from mutation or recombination events and the reacquisition of an E-154 glycosylation motif could contribute to neurovirulence (Morris et al., 2017). Both elements could account in part for differences in the replication efficiency, neuro-invasiveness, and neurotropism of the Asian ZIKV strains compared to native African strains. Codon usage adaptation to human hosts displayed by the NS1 gene of the Asian strains also seems to be an important factor, as this phenomenon is known to increase survival and higher titers and enhance immune evasion strategies. Changes in the NS1 structure between the African and Asian strains also may 
contribute to increased neuro-invasiveness and different patterns of host gene activation (Morris et al., 2017).

Since infection with ZIKV strains from the Asian lineage is associated with microcephaly and CZS in humans, it is likely that ZIKV crosses the placental barrier early in gestation. Interestingly, while the placental syncytiotrophoblast, found in mature placenta, appears mostly resistant to ZIKV, a study that compared African (MR766) and Asian strains (FSS13025, Cambodia) showed that embryonic stem cellderived trophoblasts are highly susceptible to ZIKV infection (Sheridan et al., 2017).

Ex vivo studies have shown that infections with the African strain resulted in higher replication and cell lysis, indicating that infection with the African-lineage ZIKV strain could result in an early termination of pregnancy, while infection with an Asian-lineage ZIKV strain would be less destructive and more chronic, leading to congenital malformations (Sheridan et al., 2017). Murine in vivo studies have compared the symptoms induced by African (Uganda and Senegal) and Asian (Cambodia, Malaysia, and Puerto Rico) strains in signal transducer and activator of transcription, and the African strains resulted in more weight loss, mortality, and severe prolonged neurologic symptoms compared to Asian strains. Even though ex vivo and in vivo data point toward the stronger virulence of African strains, the analysis must be done carefully, as one major challenge in interpreting and comparing the data from these studies is the lack of harmonization of the virus strains used, and most studies included the African lineage MR766 strain, which cannot be considered as a standard (Simonin et al., 2017).

ZIKV has a tropism for many human cells and tissues. It can infect the skin fibroblasts, keratinocytes and dendritic cells, monocytes, retinal pigment epithelium (RPE); brain cells including neural progenitors, neurons, astrocytes and glial cells; and uterine fibroblasts, placental cells, and testicular cells (Alpuche-Lazcano et al., 2018). Some evidence suggested that ZIKV could be more heat-stable than other flaviviruses, which may increase its ability to survive in different bodily secretions (e.g., saliva, semen) (Kostyuchenko et al., 2016). ZIKV remains detectable in blood from a few days to 1 week after the onset of symptoms and can persist longer in urine and semen. Besides, several cases of sexual transmission of the virus have been described that were related to viral shedding in semen (D'Ortenzio et al., 2016; Frank et al., 2016; Harrower et al., 2016). While the exact mechanism of sexual Zika transmission remains unknown, seeding to the male reproductive tract may occur in the context of viremia because the blood testes/deferens/ epididymis are impact barriers to viruses, especially in the presence of systemic or local inflammation. In addition, virus can persist even if it cannot replicate in the male reproductive tract because the testes are immunologically privileged and the immune response is restricted to enable sperm survival. Virus also may be transmitted to semen as a result of survival and replication within the accessory glands (Salam and Horby, 2017).

\subsection{ZIKV transmission cycles}

ZIKV primarily is transmitted to humans by mosquitoes belonging to the Aedes genus (Dick et al., 1952; Haddow et al., 2012; Musso and Gubler, 2016). As other mosquito-borne flaviviruses of public health importance, including YFV and DENV, ZIKV has two evolutionarily and ecologically distinct transmission cycles: an enzootic, sylvatic transmission cycle, where the virus circulates between arboreal Aedes spp. mosquitoes and NHP; and a human or urban cycle, where the virus circulates between human and peridomestic/domestic Aedes spp. mosquitoes (Dick et al., 1952; Haddow et al., 2012).

Mosquitoes acquire ZIKV via blood meal, and they host it throught their life span without being affected. They transmit it to the next amplification host (Schaffner et al., 2013). In Africa, ZIKV is likely maintained during interepidemic phases in sylvatic transmission cycles involving NHPs and forest-associated mosquitoes (Petersen et al., 2016a,b). Potential mosquito vectors in the African continent include $A$. africanus, A. albopictus, A. apicoargenteus, and A. furcifer (Dick et al., 1952; Faye et al., 2014; Grard et al., 2014). ZIKV main vector in the Americas is A. aegypti, which also transmits DENV, chikungunya virus (CHIKV), and YFV. However, the importance of A. albopictus (Asian tiger) in ZIKV transmission has expanded, especially in the United States. With the increased global urban expansion and human-made developments, both species have expanded their geographic range and have become associated with urban landscapes (Rochlin et al., 2013).

The World Health Organization (WHO) noted that the vector competence for A. aegypti and A. albopictus is similar, but A. alpopictus is considered to have lower vector capacity than A. aegypti (WHO, 2016a). A. aegypti feeds primarily on humans, bites several times in a single meal, has an almost imperceptible bite and lives very close to humans. A. aegypti is widespread in the tropical and subtropical regions of the world but it does not winter well in cold climates (Gubler, 2002; Gasperi et al., 2014). A. albopictus is seen in a wider geographical distribution, including subtropical and temperate climates, it is resilient and aggressive, is long lived (4-9 weeks), can survive in rural and urban environments, and is able to survive through cold winters (Medlock and Leach, 2015). A. albopictus is established in many parts of Europe, especially Mediterranean countries, and in the United States (Gasperi et al., 2014; Gardner et al., 2017). Native to Southeast Asian tropical and subtropical countries, A. albopictus has also colonized almost every Mediterranean countries and has adapted to temperate regions, spreading further north in Europe and United States, becoming a concern for populations in temperate climates (Medlock et al., 2012; Kraemer et al., 2015). A. albopictus similarities to A. aegypti, its implication in DENV and CHIKV transmission, and its distribution in Western Europe, South and East Asia and the Americas suggest an important role for this mosquito vector in ZIKV transmission around the world (Gratz, 2004; Mousson et al., 2005; Vega-Rua et al., 2013; Gardner et al., 2016). There is also evidence that genera other than Aedes such as Culex, Anopheles and Mansonia might be competente in transmitting ZIKV (Diallo et al., 2011; Epelboin et al., 2017). As A. egypti and A. albopictus thrive in stagnant water collections, proliferation may be encouraged by human population growth or migratory waves from areas with civil upheavel and uncontrolled slum formation (Vorou, 2016).

Which NHP species are involved in ZIKV sylvatic cycle in Africa is not entirely clear. From 1968 through 2002, RT-PCR analyses detected ZIKV from monkeys' blood from West Africa (Faye et al., 2014). Buechler et al. (2017) investigated ZIKV seroprevalence in 239 wild NHPs, including baboons (Papio cynocephalus from Tanzania; Papio kindae and Papio ursinus griseipes from Zambia) and African green monkeys (Chlorocebus pygerythrus from South Africa; Chlorocebus sabaeus from the Gambia) using quantitative RT-PCR (qRT-PCR) and antibody capture enzyme-linked immunosorbent assay (ELISA). The authors did not find evidence of active ZIKV infection in the animals, but described variable seropositivity of up to $16 \%$ in some of the animals' populations sampled. More ZIKV-exposed animals were seen from the northern areas of Sub-Saharan Africa, suggesting that the distribution of ZIKV infection may be determined more by environmental or geographical factors, including the prevalence of particular mosquito vectors or tropical forest conditions, than host species. In their study, evidence of ZIKV infection in areas of Africa where ZIKV had not been reported in humans or primates in over a decade point to a persisting and previously unrecognized reservoir (Buechler et al., 2017). Olson et al. (1983) also detected anti-ZIKV antibodies in ducks, goats, horses, bats, cows, and carabaos (water buffalo) from Indonesia, showing the widespread circulation of the virus in domestic animals. In Asia, samples collected in 1996 and 1997 from semi-captive orangutans in Borneo, Malaysia, detected anti-ZIKV antibodies (Wolfe et al., 2001).

In the Americas, the remarkable diversity of NHP species provides a potential to establish a sylvatic ZIKV cycle, along with more than 200 mosquito species (Bueno et al., 2016). NHP reservoirs have an essential role in ZIKV human transmission in Africa, but only recently studies 
have suggested that Neotropical primates may also be infected by ZIKV in the Americas, and that the virus can also be able to explore sylvatic cycles in the New World. That could be partly because of the high number of Aedes spp. (28 only in Brazil) and the close contact between NHPs and humans in the American continent (Bueno et al., 2016; Althouse et al., 2016; Moreira-Soto et al., 2018; Favoretto et al., 2016). Favoretto et al. (2016) tested sera and oral swabs from 15 marmosets (Callithrix jacchus) and 9 capuchin-monkeys (Sapajus libidinosus) co-inhabiting with humans, in 2015 in Ceará state (located in northeastern Brazil, an epidemic area for ZIKV). The study showed that $29 \%$ of the animals tested positively for ZIKV in RT-PCR. Moreira-Soto tested 207 NHPs in northeastern, central and central-western Brazil in urban and peri-urban setting for infection with ZIKV and CHIKV. No animal tested positive for viral RNA in genus-specific and species-specific RT-PCR assays, suggesting the absence of acute infection in all animals. However, $2.9 \%(6 / 207)$ of the animals from the families Atelidae, Callitrichidae, and Cebidae showed ZIKV-specific antibodies (Atelidae: 12.5\%; Cebidae: 1.4\%; Callitrichidae: 2.9\%). The studies from Favoretto et al. (2016) and Moreira-Soto et al. (2018) suggest that a sylvatic transmission cycle to ZIKV is possible in Brazil, but samples that are geographically representative are needed for definite conclusions.

Other modes of ZIKV transmission are sexual, perinatal, blood transfusion, and laboratory exposure. In 2016 and 2017, countries reported sexual transmission of ZIKV, comprising male to female, and male to male, through vaginal, anal and oral intercourse (Deckard, 2016; Harrower et al., 2016). Reports of blood transfusion transmission have also been published (Motta et al., 2016; Barjas-Castro et al., 2016; Slavov et al., 2017). Before the current outbreaks, 4 cases of infection were known to have occurred through laboratory exposure (CDC, 2014). Transmission through solid organ allografts has not been reported, but current evidence indicates that this is possible. There is one report of an asymptomatic infection in a liver recipient following possible transfusion-transmitted infection (Barjas-Castro et al., 2016). Besides, a case series reported 4 solid organ transplant recipients with symptomatic ZIKV infection, abnormal graft function, thrombocytopenia, and bacterial superinfection (Nogueira et al., 2017). Other possible modes of transmission still undefined include exposure to infected saliva, sweat and breast milk (Bonaldo et al., 2016; Dupont-Rouzeyrol et al., 2016).

\subsection{ZIKV seroprevalence}

Efforts to standardize study protocols are underway to establish the actual seroprevalence of ZIKV across different populations at risk. The estimated ZIKV seroprevalence in exposed populations of endemic regions has been placed at $\sim 50 \%$ and in non-exposed populations at $\sim 10 \%$, although the actual seroprevalence is largely unknown and a focus of intense research (Musso and Gubler, 2016; Van Kerkhove et al., 2016; Aubry et al., 2017; Gallian et al., 2017; Subissi et al., 2017; WHO/Institut Pasteur/ISARIC/CONSISE Version 1.10, 24 January 2017).

Studies with similar methodological protocols were conducted in French Polynesia (2014), Cameroon (2015), Bolivia (2016-2017), and Martinique Island (2016), which used ELISA to detect ZIKV IgG in blood samples. The study conducted in French Polynesia comprised the general population and schoolchildren, and found ZIKV seroprevalence rates and proportions of asymptomatic infections of $49 \%$ and $43 \%$, respectively, for participants from the general population samples in 2014 and $66 \%$ and $29 \%$, respectively, for schoolchildren sampled in 2014. Seroprevalence rates and proportions of asymptomatic infections were $22 \%$ and $53 \%$, respectively, for participants recruited in 2015 (Aubry et al., 2017). In Bolivia, between December 2016 and April 2017, 814 asymptomatic Bolivian volunteer blood donors were screened for ZIKV and analysis revealed a ZIKV seroprevalence of $39 \%-21.5 \%$ in tropical areas and around $0 \%$ in highlands (Saba
Villarroel et al., 2018). In Martinique, seroprevalence was performed at 2 times points: in 418 donors in early March 2016, and in 176 donors sampled in early June 2016. The seroprevalence after seroneutralization was $13.5 \%$ in early March and $42.2 \%$ in early June (Gallian et al., 2017). Lower rates were found in a study that evaluated 1084 blood donors in Cameroon from August to October 2015. The global seroprevalence was around $5 \%$ with risk factors associated with seropositity pointing to the existence of a local peri-sylvatic cycle of transmission (Gake et al., 2017).

Given that a considerable number of patients in the general population are expected to be asymptomatic after a ZIKV infection, the information that is being gathered by the ongoing efforts is critical to determine the real spectrum of the disease, its associations and the role that natural immunity may have in the protection, spread and pathophysiology of the infections.

It is not known if persons previously infected with ZIKV are protected against secondary infections. Also, it has been studied if antibodies to DENV are protective against ZIKV. Robbiani et al. (2017) screened sera from more than 400 donors from ZIKV epidemic areas of Brazil and Mexico for ZIKV envelope domain III (ZEDIII) binding and neutralization to investigate the antibody response in individuals who develop a high titer of anti-ZIKV antibodies. That study reported that serologic reactivity to DENV-1 EDIII before ZIKV exposure is associated with increased ZIKV neutralizing titers after exposure, indicating that these recurring antibodies cross-react with DENV-1 and ZIKV. Besides, serologic testing showed that antibodies to this region are correlated with serum neutralizing activity against ZIKV. Thus, high neutralizing responses to ZIKV may be associated with pre-existing reactivity to DENV-1 in humans (Robbiani et al., 2017).

In contrast, Collins et al. (2017) did not demonstrate frequent and high-level cross-neutralization of ZIKV after exposure to DENV; 19 persons in that study who recovered from primary DENV infections did not show cross-neutralization to ZIKV. That study also suggested that most persons infected with DENV do not maintain high levels of ZIKV neutralizing antibodies 6 months after DENV infection. The study also indicated that ZIKV neutralization activity was maintained after DENV depletion of serum from persons with primary ZIKV and was mostly preserved in depleted serum from persons with secondary ZIKV, even when neutralization activity was lost to all DENV serotypes tested.

No ZIKV licensed vaccines or antiviral therapies currently are available for treatment. Murine studies have shown that ZIKV envelope glycoproteins have been identified as candidates for vaccine development, as they are correlated with induction of potent ZIKV-specific neutralizing antibodies (Zhao et al., 2016). A ZIKV vaccine has been studied, and possible ways include developing inactivated, recombinant live-attenuated viruses; protein subunit vaccine virus-like particles; and RNA and DNA vaccines (Salvo et al., 2018). It was also reported in a murine model that neutralizing human antibody protects mice against maternal-fetal transmission, infection, and disease (Sapparapu et al., 2016).

\subsection{Clinical aspects of arboviral diseases}

The incubation period of ZIKV ranges from 3 to 14 days (Krow-Lucal et al., 2017). Asymptomatic or mild clinical forms of ZIKV, CHIKV and DENV may account for most of the infections and initial symptoms can be similar and clinically non-specific (Ioos et al., 2014). ZIKV infection is characterized by mild fever $\left(37.8^{\circ} \mathrm{C}-38.5^{\circ} \mathrm{C}\right)$, arthralgia of small joints of hands and feet, myalgia, headache, retro-orbital pain, anorexia, diarrhea, bilateral non-purulent conjunctivitis, cutaneous maculopapular rash and, occasionally, diarrhea; which usually last for less than 1 week. However, only $20 \%$ of patients with ZIKV acute infection have reported symptoms (Adibi et al., 2016; Ioos et al., 2014). Serosurvey results from Yap indicated that only $19 \%$ of persons who were infected had symptoms attributed to ZIKV (Duffy et al., 2009). During ZIKV outbreaks in French Polynesia, Martinique, and Guadaloupe the 
resulting attack rates of symptomatic ZIKV infection ranged from $23 \%$ to $46 \%$ (Subissi et al., 2017; Duffy et al., 2009).

The importance of asymptomatic transmission has also been shown for other vector-borne diseases as dengue and malaria (Duong et al., 2015; Coura et al., 2006). It has also been described that, at a given level of dengue viremia, affected individuals with no symptoms or prior to the onset of symptoms are more infectious to mosquitoes than those with symptoms (Duong et al., 2015). In ZIKV infection, asymptomatic cases with low viremia may play a role in sexual and blood transfusion transmission (Deckard, 2016; Reuters, 2016).

CHIKV, a member of the genus Alphavirus and family Togaviridae, has four serotypes: East-Central-South Africa, West Africa, Asian and Indian Ocean lineages (Nunes et al., 2015). The word chikungunya is derived from the Kimakonde word meaning "that which bends up" in reference to the stooped posture developed as a result of the arthritic symptoms of the disease (Hamer and Chen, 2014). The incubation period of CHIKV ranges from 1 to 12 days. Symptoms include fever, headache, myalgia and moderate or severe arthralgia that affects extremities. Duration of joint pain can vary from few days to years, resulting in acute, subacute or chronic disease (Paixão et al., 2018).

Dengue has four serotypes (DENV-1, DENV-2, DENV-3 and DENV4), and multiple lineages of each serotype. Infection with one serotype provides long immunity against that particular serotype; cross immunity to the others is temporary and may lead to increased severity (Weaver and Vasilakis, 2009; Rigau-Pérez et al., 1998). The incubation period of dengue ranges from 3 to 14 days. Although most of the cases are self-limiting, patients usually present with high fever, retro-orbital pain, skin rash, myalgia and headache, and in some cases with mild haemorrhagies. Severe forms of the disease can manifest with hemorrhage, thrombocytopenia, liver injury and, in some cases, death (Paixão et al., 2018).

WNV is the most common vector-borne viral disease in the United Stardes, with 2205 cases reported in US in 2014. Symptomatic WNV is usually self-limited, nonspecific, and includes fever and maculopapular eruption. The neuroinvasive form leads to flaccid paralysis, typically with meningoencephalitis. GBS also has been associated with WNV. Neuroinvasive infection can be diagnosed by detecting WNV IgM antibodies in the serum of cerebrospinal fluid (CSF). Cross-reactivity with other flaviviruses is common (Lindsey et al., 2015). Vertical transmission has been described in WNC, resulting in congenital chorioretinal scarring and central nervous system (CNS) malformation (Alpert et al., 2003).

During a ZIKV outbreak in French Polynesia a 20 -fold increase in GBS was observed compared with the previous 4 years (Cao-Lormeau et al., 2016). GBS, an acute, immune-mediated polyradiculoneuropathy typically occurring after minor viral and bacterial infections, is characterized by rapidly progressive symmetrical weakness, areflexia, sensory disturbances, and involvement of cranial nerves that can cause death (Van den Berg et al., 2014; Schuler-Faccini et al., 2015; Vorou, 2016). The WHO (2016b) stated in March 2016 that there is "scientific consensus that ZIKV is a cause of microcephaly and GBS," although the causal relationship and the pathophysiology of these disorders remain unknown. Additional countries that reported an unusual increase of GBS cases associated in time and place with Zika included Brazil, Suriname, Panama, El Salvador, Venezuela, Honduras, and others (WHO, 2018). Uveitis and unilateral acute maculopathy also have been described in adults after ZIKV acute infection (Furtado et al., 2016; Kodati et al., 2016; Parke et al., 2016).

\subsection{ZIKV diagnostic testing}

RT-PCR in serum is the main test for ZIKV, CHIKV, WNV, and DENV during the initial viremic phase. However, detection of ZIKV RNA in serum is limited to the first 5 days, and in urine up to 20 days. Laboratory diagnosis is challenging because of low viremia and crossreactivity of ZIKV antibodies with other flaviviruses (Gourinat et al.,
2015). For persons with suspected ZIKV infection, a positive RT-PCR result confirms ZIKV infection, and no antibody testing is recommended (FDA, 2016). However, due to the decline in the level of viremia over time, a negative RT-PCR does not exclude infection. Therefore, serum IgM antibody testing for ZIKV and DENV should be performed if RTPCR is negative (Rabe et al., 2016).

ZIKV specific IgM antibodies develop during the first week of illness (Bingham et al., 2016; Lanciotti et al., 2008). Data on duration of IgM antibody response following ZIKV are limited. Neutralizing antibodies to ZIKV develop shortly after IgM antibodies and consist primarily of IgG antibodies. Neutralizing antibodies are expected to persist for many years after flavivirus infections and are believed to confer prolonged, possibly lifelong, immunity (Whitehead et al., 2007; Busch et al., 2008; Poland et al., 1981). An ELISA assay can be used to detect anti-ZIKV IgM antibodies in serum or CSF; however, ZIKV IgM ELISA can provide false-positive results because of cross-reacting IgM antibodies against other flaviviruses. For specimens collected from 7 days to 12 days after onset of symptoms, a negative IgM antibody result to both ZIKV and DENV rules out recent infection with either virus (Rabe et al., 2016). If either ZIKV and DENV IgM antibody are positive, equivocal, or inconclusive, plaque reduction neutralization test (PRNT) should be performed. A PRNT using a $90 \%$ cutoff value with a titer $\geq 10$ against ZIKV, together with negative PRNTs (i.e., $<10$ ) against other flaviviruses confirmatory for recent infection with ZIKV (Rabe et al., 2016).

For asymptomatic pregnant women living in an area with local ZIKV transmission, IgM testing should be performed upon initiation of prenatal care, mid-second trimester, and if any fetal abnormalities are detected during ultrasound evaluation (Petersen et al., 2016b). For asymptomatic pregnant women with a history of travel to areas where ongoing ZIKV transmission is occurring, ZIKV antibody testing should be performed on specimens collected 2-12 weeks post travel (Petersen et al., 2016b). If a serum specimen was collected $>12$ weeks after travel, although IgM might still be present, it is possible that antibody levels have dropped below the detectable limit (Rabe et al., 2016).

\subsection{CZS and microcephaly}

The recent association between ZIKV infection in pregnant women and an epidemic of microcephaly (head circumference of 2 or more standard deviations below the mean for age and sex) among neonates in Brazil in 2015 has attracted global attention (Schuler-Faccini et al., 2015; Ministério da Saúde do Brasil, 2016a). In 2015, 1248 suspected new cases of microcephaly were registered in Brazil, representing a 20fold increase compared to recent years, and the Brazilian Ministry of Health associated this increased prevalence with maternal-fetal ZIKV transmission (Ministério da Saúde do Brasil, 2016b). Microcephaly cases after ZIKV local infection also have been reported in Cape Verde, Guinea-Bissau, Thailand, Colombia, Venezuela, French Polynesia, Martinique, Panama, and Puerto Rico. Other cases were reported in Slovenia and the US in mothers who traveled to Brazil or countries with ongoing ZIKV outbreaks during pregnancy (WHO, 2016c; WHO, 2018).

Centers for Disease Control and Prevention (CDC) established the U.S. Zika Pregnancy Registry (USZPR) in 2016 to monitor pregnant women with laboratory evidence of ZIKV infection and their infants in the 50 US States and the District of Columbia. From January 2015 through December 2016, 1297 pregnancies with possible recent ZIKV infection were reported to the USZPR from 44 states, including 972 completed pregnancies with reported outcomes (895 liveborn infants and 77 pregnancy losses). Among the completed pregnancies, $62 \%$ of the pregnant women were asymptomatic, $36 \%$ were symptomatic, and $3 \%$ had missing symptom information. Among symptomatic women, gestational timing of ZIKV infection was calculated using symptom onset date. Among asymptomatic women, the trimester of exposure was calculated using dates of travel to areas of active ZIKV transmission or sexual exposure. Birth defects were reported for 51 (5\%) of the 972 completed pregnancies with laboratory evidence of possible recent 
ZIKV infection. Birth defects were reported in similar proportions of fetuses and infants whose mothers did and did not report symptoms of ZIKV disease during pregnancy. Brain abnormalities and/or microcephaly were reported in $43(84 \%)$ of 51 fetuses/infants with birth defects. Among pregnancies with confirmed ZIKV infection, brain abnormalities and/or microcephaly were reported in 18 (75\%) of $24 \mathrm{fe}-$ tuses/infants with birth defects. The 51 fetuses or infants with birth defects were from pregnancies with ZIKV exposure from the following 16 countries/territories with ongoing active ZIKV transmission by the time of the study: Barbados, Belize, Brazil, Cape Verde, Colombia, Dominican Republic, El Salvador, Guatemala, Guyana, Haiti, Honduras, Jamaica, Mexico, Puerto Rico, Republic of Marshall Islands, and Venezuela (CDC, 2017). Because of the increase in congenital microcephaly and other neurologic disorders in the Americas, the WHO declared ZIKV infection a public health emergency of international concern on February 1, 2016, which lasted until December 2016 (WHO, 2016c).

The mechanism by which ZIKV causes fetal brain abnormalities is unknown. Reports have indicated that the virus can evade the normal placental immunoprotective response (Adibi et al., 2016). A large body of evidence supports ZIKV neurotropism and interaction with neural progenitor cells (NPC) and glia. (Alvarado and Schwartz. 2017; Mlakar et al., 2016; Schwartz, 2017; Tang et al., 2016; Aleman et al., 2017; Roach and Alcendor, 2017; Martines et al., 2016; Retalack et al., 2016; Dang et al., 2016; van den Pol et al., 2017), although the exact mechanism remains a focus of active research. Aagaard et al. (2017) have shown that the placenta is highly permissive to ZIKV and may work as a reservoir for viral replication; and Mladinich et al. (2017) revealed that ZIKV persistently infects and continuously replicates in primary human brain microvascular endothelial cells (hBMECs) and suggested a direct mechanism for ZIKV to cross the blood-brain barrier (BBB).

ZIKV infection during the first trimester of pregnancy can lead to CZS in about $1-13 \%$ of the cases. Maternal ZIKV infection during early pregnancy can be associated with stillbirth, miscarriage, fetal growth restriction, CNS abnormalities, and ocular abnormalities (Johansson et al., 2016; Zare Mehrjardi et al., 2017). Theoretically, the virus would have a more difficult access to the fetus in the late pregnancy, as it should pass through the trophoblastic cell layers, chorionic and amniotic membranes, before reaching the fetus (Mysorekar \& Diamonds, 2016). Besides, primary human trophoblast (cytotrophoblast and syncytiotrophoblast) can release lambda interferon (IFN- $\lambda$ ) during the late pregnancy which has antiviral property, protecting the trophoblastic and non-trophoblastic cells of the term placenta to become infected (Rosenberg et al., 2016). ZIKV infection during pregnancy can increase placental permeability by inducing trophoblast apoptosis and vascular damage, as seen in other TORCHES-type chronic placentitis. The placental tissue of spontaneous abortions and affected newborns reveal villous edema, increased number of Hofbauer cells, increased fibrin deposition, lymphohistiocytic intervillositis, and chorionic villi dystrophic calcifications and sclerosis. These placental changes can cause growth restriction and fetal demise (Noronha et al., 2016; Rosenberg et al., 2016; Zare Mehrjardi, 2017).

In the TORCHES (toxoplasmosis, rubella, cytomegalovirus, herpes simplex virus and other infections including syphilis), immunoglobulin M (IgM) maternal antibodies are not protective against fetal infection since IgM does not cross the placenta or blood-brain barrier (Fung and Tilton, 1985). Evidence show that the same may happen for ZIKV vertical transmission. Cordeiro et al. (2016) collected blood samples from 42 mothers and neonates with microcephaly, and CSF specimens from 30 neonates. Molecular assays were performed for detection of ZIKV, DENV, and CHIKV; IgM ELISA assays and PRNTs were performed to detect ZIKV and DENV. None of the mothers or babies had IgM antibodies to DENV. However, $83 \%$ of the mothers and their babies had DENV IgG antibodies in serum. Thirteen of 42 mothers (31\%) had ZIKV IgM antibodies detected in serum, and 29 of 42 (69\%) were negative. As these 26 IgM-negative mothers reported rash during the first trimester of pregnancy, the authors suppose that ZIKV infection would have occurred at least 6 months before birth. In neonates, 38 of 42 (90.5\%) of serum specimens were positive for ZIKV IgM antibodies, and, 4 neonates $(9.5 \%)$ had ZIKV IgM-negative samples. ZIKV IgM antibodies were detected in $97 \%$ samples of CSF from neonates with microcephaly. As maternal IgM is not transplacentally transferred to the fetus, the detection of ZIKV-specific IgM in the CSF indicates that the neonates had a congenital ZIKV infection.

Transplacental transmission occurs following primary infection of a seronegative mother during pregnancy. Maternal IgM antibodies, unable to cross the placenta, form first, and protective IgG antibodies, which are able to cross the placenta, have not yet been formed. So, the infant is not protected from infection via the placenta. Cordeiro et al. showed that the presence of ZIKV and DENV IgG in the neonates indicate maternal IgG transference (Cordeiro et al., 2016). On the other hand, a recent study by Caires-Júnior et al. (2018) investigated discordant CZS twins and demonstrated a highly increased susceptibility to the pathological effects of ZIKV infection in the affected twin compared to the non-affected. Despite not being able to find a major locus associated with this condition, they suggested a multifactorial disorder.

The features reported in CZS are microcephaly (brain disruption sequence, partially collapsed skull, overlapping cranial sutures, prominent occipital bone, redundant scalp skin, and neurologic impairment); brain abnormalities (cerebral cortex thinning, abnormal gyral patterns, increased fluid spaces, subcortical calcifications, corpus callosum anomalies, reduced white brain matter, and cerebellar vermis hypoplasia); ocular findings (macular scarring, focal pigmentary retinal mottling, chorioretinal atrophy, microphthalmia, iris coloboma, lens subluxation, cataract, congenital glaucoma, optic nerve hypoplasia/ atrophy, and increased cup-to-disc ratio); congenital contracture (unilateral or bilateral clubfoot and arthrogryposis multiplex, motor disabilities, and hypotonia); hearing impairment, early hypertonia, irritability or excessive crying, tremors, swallowing dysfunction, and epilepsy (Moore et al., 2017; van der Linden et al., 2016a; de Paula Freitas et al., 2016; Ventura et al., 2016a-d; Miranda et al., 2016).

Recent evidence also has expanded the spectrum of CZS and includes children with severe brain abnormalities without microcephaly at birth (Ventura et al., 2016d, e; França et al., 2016; van der Linden et al., 2016b). The eye, as an extension of the brain, can present with anterior and posterior segment abnormalities in up to $70 \%$ of infants with CZS (de Paula Freitas et al., 2016; Ventura et al., 2016a-e; Zin et al., 2017; de Paula Freitas et al., 2017b). Concernly, despite mild clinical symptoms in the mother, ZIKV infection during pregnancy can be deleterious to the fetus and is associated with fetal death, fetal growth restriction, and CNS abnormalities (Brasil et al., 2016). Besides, microcephaly is not a reliable indicator of CZS. According to a study, the sensitivity of microcephaly alone to detect definite or probable cases was $83 \%$, which increased slightly to about $87 \%$ when a history of rash in the mother was considered (Mani, 2016). Zin et al. (2017) also reported that 10 of 24 eye abnormalities (41.7\%) occurred in the absence of microcephaly in RT-PCR-confirmed cases of CZS.

\section{Pathophysiology of the ocular disease}

\subsection{Results from experimental studies}

Miner et al. (2016) described the first animal model of ZIKV-induced eye abnormalities resulting from subcutaneous injection of ZIKV in immunocompromised, type I IFN receptor mice. Analysis of the ZIKV-infected mice revealed conjunctivitis, panuveitis, and infection of the cornea, iris, optic nerve, and ganglion and bipolar cells. The authors also detected viral RNA in tears, suggesting that virus may be secreted from lacrimal glands or shed from the cornea. ZIKV infection caused panuveitis without important damage to the retinal structures. The authors did not detect pathological ocular abnormalities in neonate mice submitted to congenital infection. 

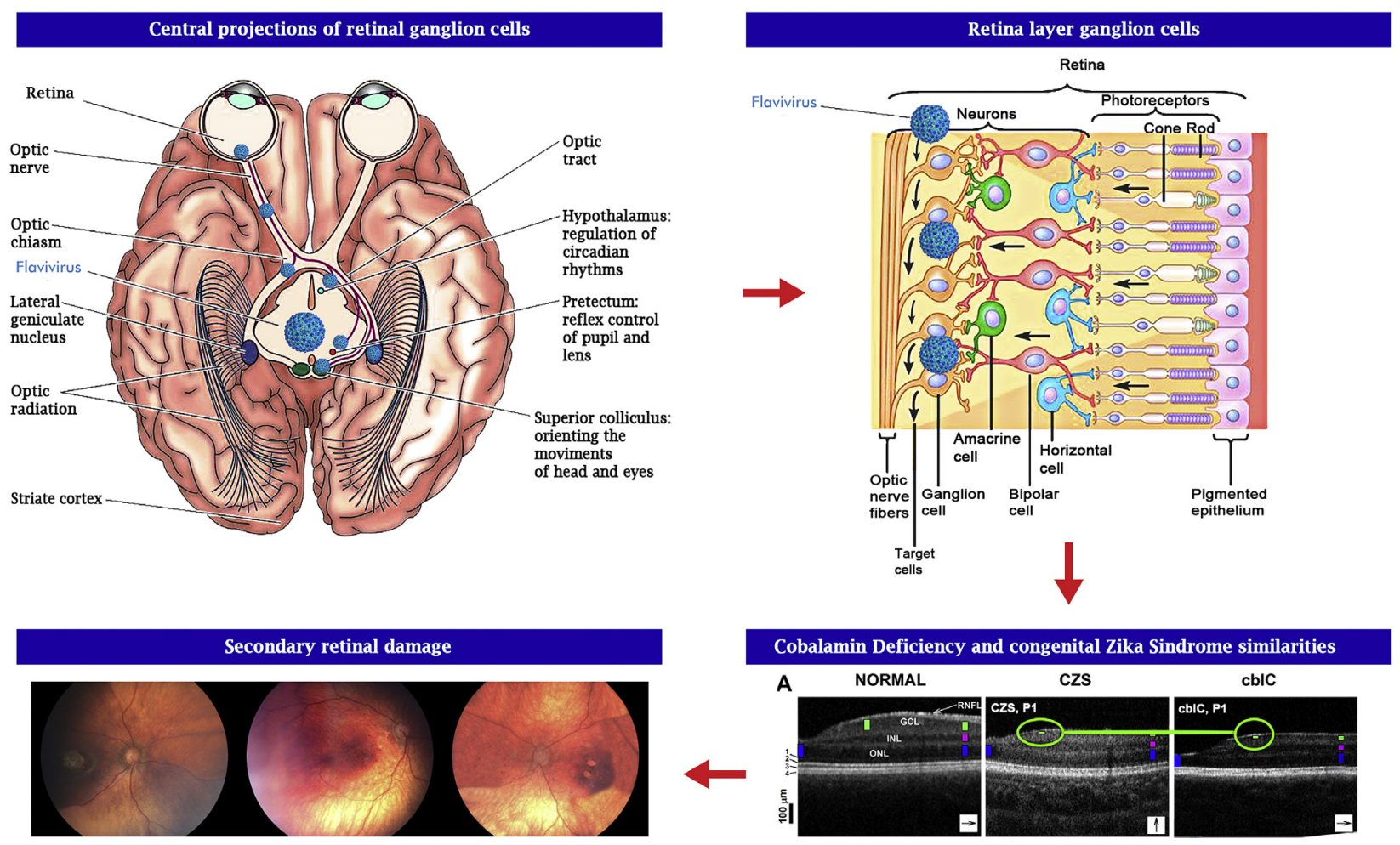

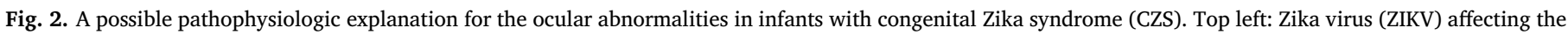

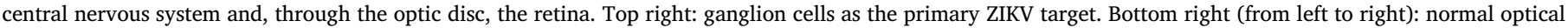

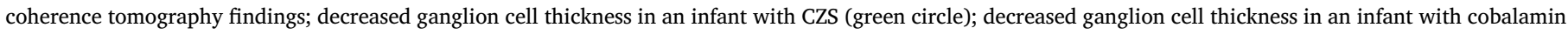
C deficiency (green circle) (Aleman et al. 2017). Bottom left: retinal lesions in infants with CZS (Ventura et al., 2016a).

Singh et al. (2017) described in an in vitro study from cultured cells that the blood-retinal barrier, the RPE, and the retinal endothelium were permissive and susceptible to ZIKV replication and cellular death. In the same study, direct inoculation of ZIKV in adult mouse eyes resulted in white subretinal lesions with soft edges radiating from the optic discs within $24 \mathrm{~h}$. As disease progression at 72 and $96 \mathrm{~h}$, the subretinal lesions exhibited RPE atrophy and pigment mottling within large fibrotic chorioretinal scars, suggesting that cells lining the bloodretinal barrier, retinal endothelium, and RPE were highly permissive and susceptible to ZIKV-induced cell death.

In another experimental study, when mice were inoculated via the intraperitoneal route with two ZIKV strains (Zhao et al., 2017), only young mice developed viral infiltration, posterior uveitis, and damage to the photoreceptor neurons and retinal ganglion cells. ZIKV preferentially infected the RPE and Müller cells, impaired their neurotrophic functions, and elicited retinal inflammatory responses. When 11-week-old mice were infected, no viral staining was found in the retina. Data from this study suggested that, before the blood-retinal barrier and host immunity are well developed, ZIKV may enter the retinal tissue and infect susceptible cellular populations.

\subsection{Histopathological features of eyes from infants with CZS}

One study analyzed the histopathological features of eyes from deceased fetuses diagnosed with CZS. In this observational case series, histopathological and immunohistochemical analyses were performed on the ocular tissue samples of four deceased fetuses (21.5-29 weeks gestational age) with CZS (Fernandez et al., 2017). CZS was confirmed in the four cases through RT-PCR and/or immunohistochemical analysis of brain tissue. In the four cases, histopathology showed a pupillary membrane, immature anterior chamber angle, and no differentiation of the nuclear layers of the neural retina, findings that could be attributed to gestational age. Besides, the four eyes presented with a thin photoreceptor layer, pigment loss and RPE thinning, perivascular inflammatory infiltrate in the choroid, and choroidal thinning, which is hypothesized to be related to ZIKV infiltration of the retinal and choroidal tissues. Results from the optical coherence tomography (OCT) study published by Ventura et al. (2016f) correlated the OCT features, including discontinuation of the ellipsoid zone and hyperreflectivity underlying the RPE because of atrophy, retinal thinning, and colobomatous-like excavation, which could result from thinning/absence of the photoreceptor layer and pigment loss and thinning of the RPE observed in the histopathological study.

Studies have shown that ZIKV might have a tropism for some tissues, including the placental, fetal brain tissue, and retina in previous studies (Mlakar et al., 2016; Ritter et al., 2017; Martines et al., 2016). Fernandez et al. (2017) supported the idea that the virus could reach the retina through two different pathways. From the placenta, the virus could reach the fetal circulation and infect the RPE, retinal endothelial cells, and the retina (Singh et al., 2017). The other pathway would be through axonal transport into the eye along the optic nerve (van den Pol et al., 2017; Aleman et al., 2017), leading to ganglion cell layer (GCL) loss, foveal maldevelopment, and sharply delineated central chorioretinal abnormalities. Experimental study conducted by van den Pol et al. (2017), demonstrated the involvement of progenitor neural cells by ZIKV in mice, causing cell death. It was possible to identify damage caused by ZIKV throughout the entire visual system, including retina, optic chiasm, suprachiasmatic nucleus, lateral geniculate nucleus, and/or the superior colliculus.

Supported by murine models of congenital ZIKV infection that showed evidence of ZIKV neurotropism and OCT evidence of in vivo primary retinal ganglion cell loss, we hypothesized that neonates exposed to ZIKV during pregnancy may have foveal maldevelopment and central chorioretinal atrophy secondary to ganglion cell loss (Aleman et al., 2017). As the retina is an extension of the diencephalon accessible with OCT in vivo microscopy, it is reasonable that the ganglion 
cells may be a major viral target, leading posteriorly to retinal abnormalities (Fig. 2). A better pathophysiologic understanding of the ocular disease may be helpful for understanding the neurodevelopmental abnormalities in CZS and for developing treatment strategies for this disease. These findings may raise discussions in Ophthalmology about viral infectious agents that can lead to ocular abnormalities.

\section{CZS eye-related abnormalities and fast spread of the disease}

Ventura et al. (2017a,b) showed that regardless of the structural ocular manifestations, children with CZS may have low visual acuity (VA). The results of this study suggested that visual impairment most likely results from CNS damage. Cortical visual impairment (CVI) is visual impairment related to brain abnormalities and damage to visual process centers and visual pathways. Children with CVI have varying degrees of VA impairment, ranging from no light perception to mild visual loss. Other neurologic findings such as microcephaly, cerebral cortical malformation, and subcortical calcifications contribute to low VA in these patients.

van den Pol et al. (2017) conducted an experimental study that showed involvement of progenitor neural cells by ZIKV in mice, causing cellular death. It was possible to identify the damage caused by ZIKV throughout the entire visual system, including the retina, optic chiasm, suprachiasmatic nucleus, lateral geniculate nucleus, and/or the superior colliculus.

\subsection{Ophthalmic manifestations of CZS in Brazil}

Studies from the two epicenters of ZIKV epidemic, Recife City in Pernambuco State, and Salvador city in Bahia State, both in northeastern Brazil, have expanded the knowledge about the devastating ZIKV consequences in the CNSs of infants born from mothers that acquired the infection during pregnancy. In 2015, ZIKV outbreaks also occurred in Rio de Janeiro and São Paulo in southeastern Brazil and Colombia and Venezuela, and investigators published studies about the ocular manifestations in CZS with important findings. All infants with CZS reported in those studies were born between May and December 2015. Table 1 shows the cities and countries where the studies were conducted and the number of patients, key ophthalmic findings, and systemic findings.

In all studies, the detailed clinical histories included the prenatal and postnatal history and maternal systemic history. Children of mothers who reported illicit drug or alcohol use during pregnancy and those with a family history of microcephaly, familial genetic disease, or consanguinity were excluded. Most studies included only children with microcephaly. However, because the spectrum of CZS also has expanded to children without microcephaly, babies without microcephaly presenting with CNS abnormalities were included in studies from Recife (Ventura et al., 2016d; van der Linden et al., 2016b) and in a large case series from Rio de Janeiro (Zin et al., 2017). The differential diagnosis in CZS includes other congenital infections such as: toxoplasmosis, rubella, cytomegalovirus (CMV), herpes simplex virus (HSV), syphilis (TORCHES), and human immunodeficiency virus (HIV). All studies that evaluated the ocular findings in CZS used a similar methodology for ruling out other congenital infections through serologic analyses in infants and their mothers. Children who tested positive for syphilis or HIV or who presented with high titers of IgG antibodies or IgM antibodies specific to toxoplasmosis, CMV, HSV, or rubella were not included. The suspected diagnosis of CZS also was based on the maternal clinical features during pregnancy, including cutaneous rash, fever, arthralgia, headache, itchiness, and malaise.

Until 2016, when some studies from Recife and Salvador were published (Ventura et al., 2016a; b; de Paula Freitas et al., 2016; Verçosa et al., 2017), ZIKV serology was unavailable in Brazil. However, the infants had a high presumptive diagnosis of CZS because they presented with microcephaly, cerebral calcifications detected by computed tomography (CT) scans, negative serology for other infectious diseases, and no history of familial genetic diseases (that could cause microcephaly) or alcoholism during pregnancy.

Twenty-four (60\%) infants from a case series from Recife underwent CSF testing for ZIKV and DENV using the IgM antibody-capture indirect ELISA (Ventura et al., 2016c). This method followed the CDC protocol described by Martin et al. (2000). In other reports of children with presumptive CZS and ocular abnormalities, the infants had a presumed diagnosis based on the clinical features of the newborns and maternal symptoms during pregnancy without serologic testing (Campos et al., 2016; Miranda et al., 2016; Yepez et al., 2017; Verçosa et al., 2017).

In Salvador, in December 2015, when one of the studies was conducted, serologic testing for ZIKV infection also was unavailable (de Paula Freitas et al., 2016). Since the study results were published, testing of seven of 10 infants with ocular findings showed that all seven babies had anti-ZIKV-specific IgM antibodies. The serum samples were tested by ELISA anti-ZIKV IgM at the Laboratory of Serology II, Department of Arbovirology and Hemorrhagic Fever, Evandro Chagas Institute, following a protocol previously described by Clark and Casals (1958). Two infants evaluated at the Federal University of São Paulo (São Paulo, Brazil) also underwent serologic testing for ZIKV antibodies with the antibody-capture indirect ELISA method (de Oliveira Dias et al., 2017).

PCR was not performed in Recife, Salvador, or São Paulo, because the virus is expected to be detected in blood only up to 5 days with PCR after clinical onset and up to 20 days in urine after clinical onset (Campos et al., 2015; Gourinat et al., 2015). In the cohort from Rio de Janeiro, all children were screened for ZIKV with RT-PCR (Zin et al., 2017), and the virus was identified in maternal blood, urine, amniotic fluid, and/or placental tissue samples. In that study, infants whose mothers tested negative or had no ZIKV RT-PCR results were excluded.

In all studies, the mothers and infants underwent an external ocular examination, biomicroscopy, and dilated indirect ophthalmoscopy. After pupillary dilation, the infants underwent an examination using a wide-field digital imaging system (RetCam Shuttle, Clarity Medical Systems, Pleasanton, CA, USA; or PanoCam ${ }^{\mathrm{TM}}$ LT Wide-field Digital Imaging System, Visunex Medical Systems, Fremont, CA, USA) to document the optic nerve, retinal, and choroidal abnormalities.

3.1.1. Ocular abnormalities in children with CZS from Northeastern Brazil

Ventura et al. (2016a) first described in the medical literature the ophthalmic findings in three children with CZS, all born in Recife, in Pernambuco State, northeastern Brazil, the epicenter of the ZIKV infection, and evaluated at the Altino Ventura Foundation. The infants presented with cerebral calcifications detected by CT scans and had a presumed diagnosis of intrauterine ZIKV infection based on CNS and ocular findings. Only one mother reported rash and arthralgia during the first trimester of pregnancy; no mother had ocular lesions suggestive of active or previous infection. The three infants had unilateral findings that included gross macular pigment mottling and foveal reflex loss. Well-defined macular chorioretinal atrophy was detected in one child.

Ventura et al. (2016b) also described the ocular findings in 10 other infants with microcephaly due to presumptive CZS born in Recife and the mothers. The mothers' ocular examinations were also normal. Seven mothers had DENV-like symptoms in the first or second trimester. The infants had normal anterior-segment structures and normal ocular axial lengths. One $(10 \%)$ child had horizontal nystagmus, four (40\%) exophoria, and two (20\%) esophoria. Seventeen (85\%) eyes had optic nerve and macular abnormalities. The optic nerve alterations included the double-ring sign, pallor, and increased cup-to-disc ratio. The macular abnormalities included foveal reflex loss, mild-to-gross pigment mottling, and sharply demarcated circular areas of chorioretinal atrophy.

Campos et al. (2016) reported the ocular findings in a 1-month-old infant with presumed CZS born via spontaneous vaginal delivery at 38 


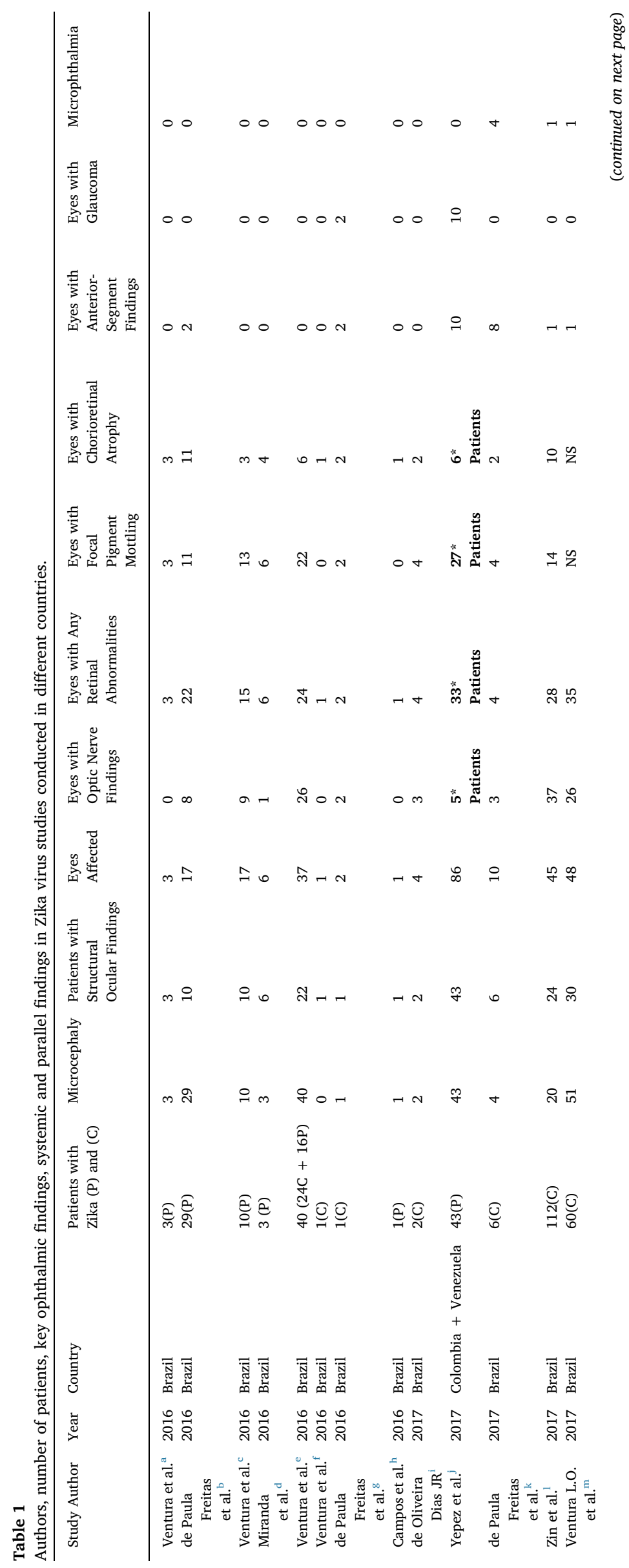




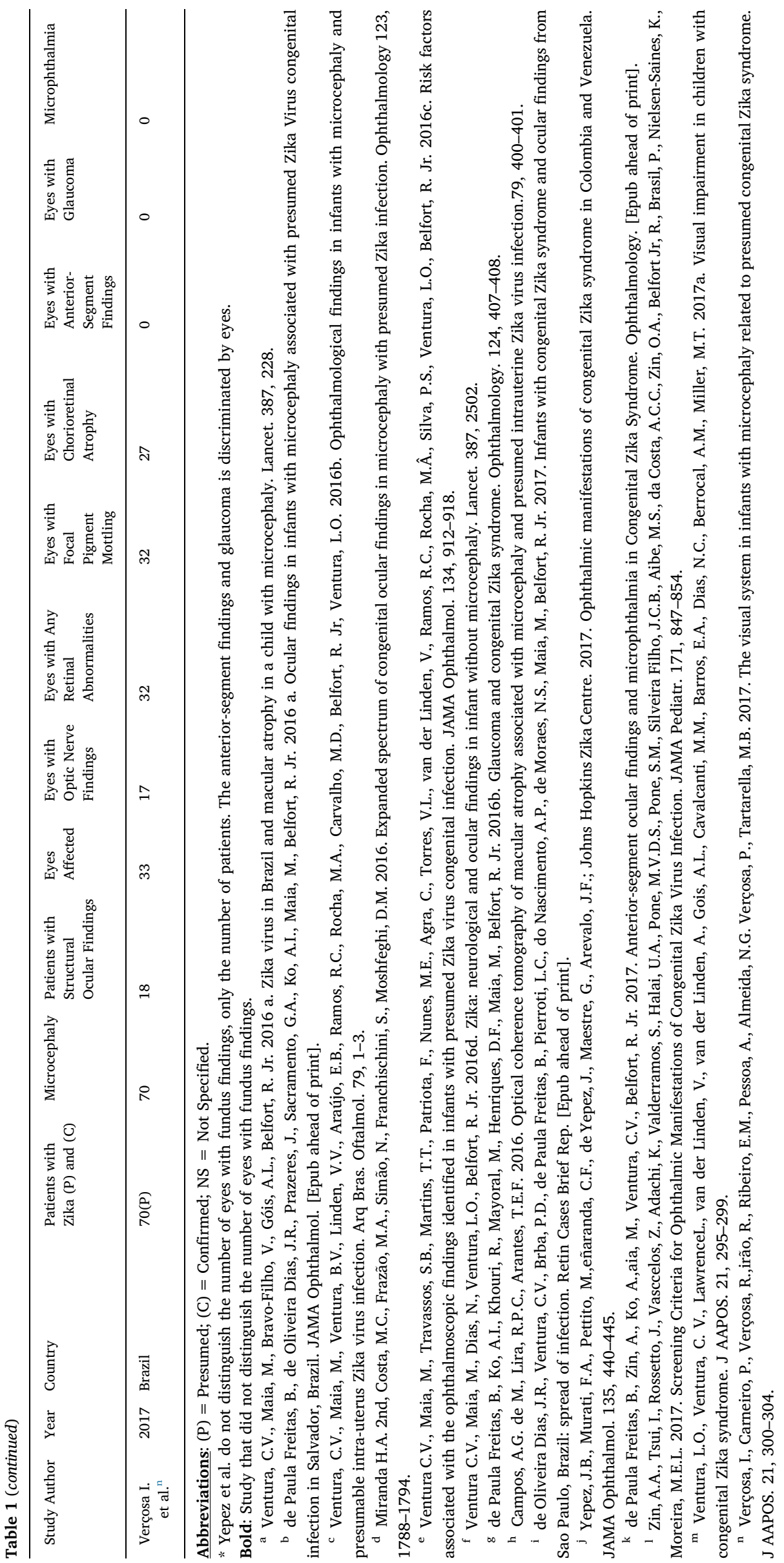


weeks gestation. The child presented with well-defined chorioretinal atrophy in the macula of the left eye.

Subsequently, Miranda et al. (2016) expanded the spectrum of ocular findings in children with presumed CZS. The report, which included three microcephalic babies, showed that all children had pigmentary maculopathy ranging from mild to pronounced. In four eyes, well-delineated macular chorioretinal atrophy with a hyperpigmented ring was present. Three eyes had vascular tortuosity, two eyes early termination of the retinal vasculature, two washed out peripheral retina, one scattered subretinal hemorrhages external to the macula, and one peripheral pigmentary changes associated with clustered atrophic lesions resembling grouped albinotic spots (polar bear tracks).

Ventura et al. (2016d) reported an infant (age at examination, 57 days; head circumference, $33 \mathrm{~cm}$; weight at birth, $3500 \mathrm{~g}$; gestational age at birth, 38 weeks) with CZS and ocular abnormality without microcephaly at birth. The infant had lower and upper limb spasms at birth. CT scans showed cerebral calcification in the basal ganglia, ventriculomegaly, and lissencephaly. IgM antibody capture MAC-ELISA of the CSF was positive for ZIKV, confirming the diagnosis of CZS. A chorioretinal scar was detected in the macular region of the left eye. Figs. 3 and 4 show abnormal fundus examples from infants with CZS infected and born in Recife.

In Fortaleza city, Ceará State, Northeastern Brazil, Verçosa et al. (2017) described the ocular findings in 70 infants with microcephaly due to presumed CZS. Of these, 25 (mean age, 3 months) (36\%) had ophthalmologic findings related to CZS: 18 (26\%) had intraocular abnormalities, including macular chorioretinal atrophy, mottled RPE, and optic nerve pallor; seven patients $(10 \%)$ had strabismus or nystagmus. The VA was below normal in all 11 infants; the anterior segment was normal in all patients. Fifteen mothers had symptoms associated with ZIKV infection in the first trimester of pregnancy; six were asymptomatic. One study limitation was the lack of laboratory evidence based on specific serologic testing to confirm ZIKV vertical infection.

de Paula Freitas et al. (2016) reported ocular findings in $29 \mathrm{mi}-$ crocephalic infants aged 1-6 months who were infected with CZS and born in 2015 and their mothers in Salvador, Bahia state, Northeastern Brazil. Twenty-three (79.3\%) of the 29 mothers reported ZIKV-associated systemic symptoms, including cutaneous rash (72.4\%), fever (44\%), arthralgia (37.9\%), headache (17.2\%), and itchiness $(13.8 \%)$.
No mothers reported conjunctivitis during pregnancy. Among 23 mothers who reported symptoms during pregnancy, 78.3\% had ZIKV symptoms during the first trimester, $17.4 \%$ during the second trimester, and $4.3 \%$ during the third trimester. All mothers had normal ocular examinations. Ocular abnormalities were observed in $34.5 \%$ of the children, including 17 (85\%) of 20 eyes of 10 children; and the alterations were bilateral in $70 \%$ of the affected eyes. Anterior ocular abnormalities included lens subluxation in one (5.9\%) eye and bilateral iris coloboma in one $(11.8 \%)$ patient with lens subluxation. The most common posterior findings were focal pigment mottling and chorioretinal atrophy in $64.7 \%$ of the eyes. Severe chorioretinal atrophy involved the macula in three eyes, the nasal retina in additional three eyes, and the paramacular area in five eyes. Figs. 5 , and 7 show the fundus findings in infants from Salvador with CZS.

\subsubsection{Ocular abnormalities in children with CZS from southeastern Brazil}

de Oliveira Dias et al. (2017) described the ocular findings in two infants with CZS who were infected and born in São Paulo State, Brazil, outside the primary outbreak region. In São Paulo State, almost 4000 cases of ZIKV acute infection were reported from January to November 2016 (Secretaria de Saúde do Estado de São Paulo, 2016). Both infants were IgG-positive for ZIKV and the mothers' ocular examinations were normal. The anterior-segment structures and axial lengths were normal in both children. One child (age at examination, 23 days; head circumference, $30 \mathrm{~cm}$; weight at birth, $3040 \mathrm{~g}$; gestational age at birth, 39 weeks) presented with an increased cup-to-disc ratio in both eyes, and macular chorioretinal atrophy with hyperpigmented borders and gross pigment mottling in the right eye, and extensive chorioretinal atrophy with a colobomatous-like aspect in the entire temporal quadrant of both eyes surrounded by hyperpigmented borders and gross pigment mottling. Spectral-domain OCT of the right eye showed complete excavated chorioretinal atrophy with a colobomatous-like aspect. The other patient (age at examination, 7 months; head circumference, $30 \mathrm{~cm}$; weight at birth, $3940 \mathrm{~g}$; gestational age at birth, 42 weeks) presented with gross pigment mottling in the paramacular location bilaterally surrounded by hypopigmented areas. The periphery was normal bilaterally.

These two cases were the first published autochthonous cases of children with CZS and positive ocular findings from southeastern Brazil, which confirmed the spread of the infection throughout Brazil. The

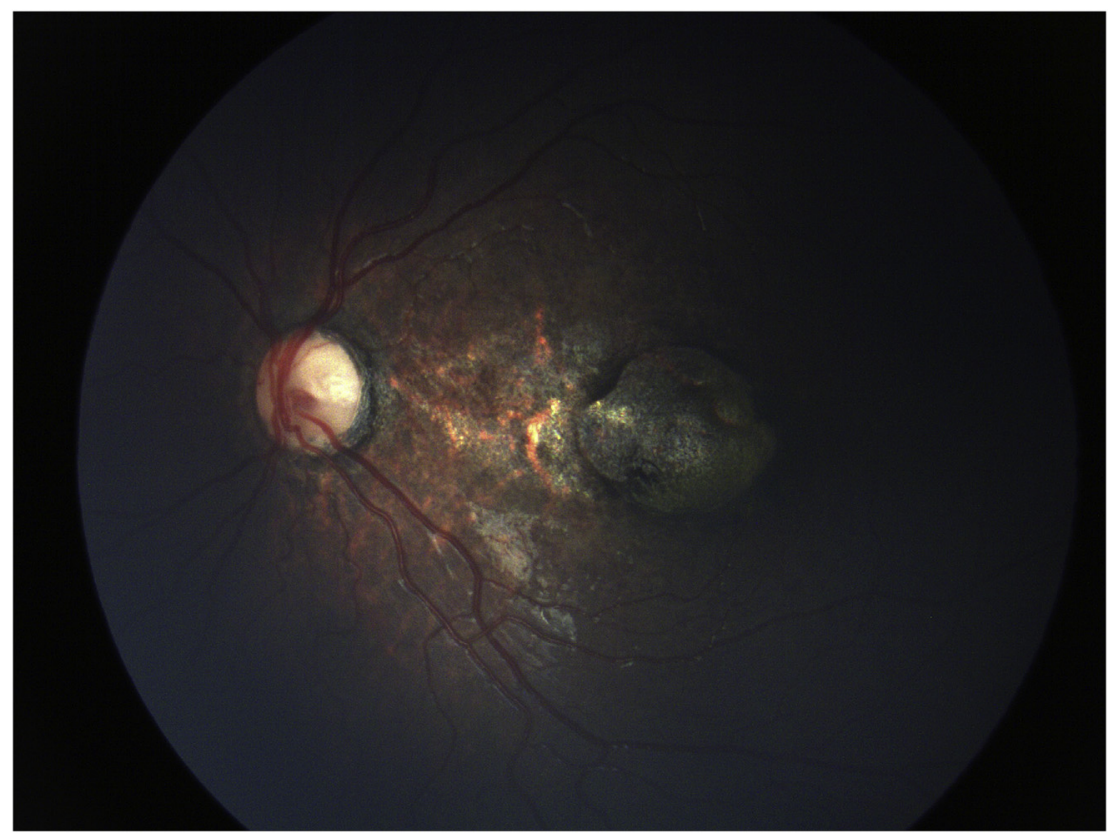

Fig. 3. A wide-angle fundus image (RetCam) of the left eye of an infant with congenital Zika syndrome shows increased cup-to-disc ratio and sharply demarcated macular chorioretinal atrophy. 


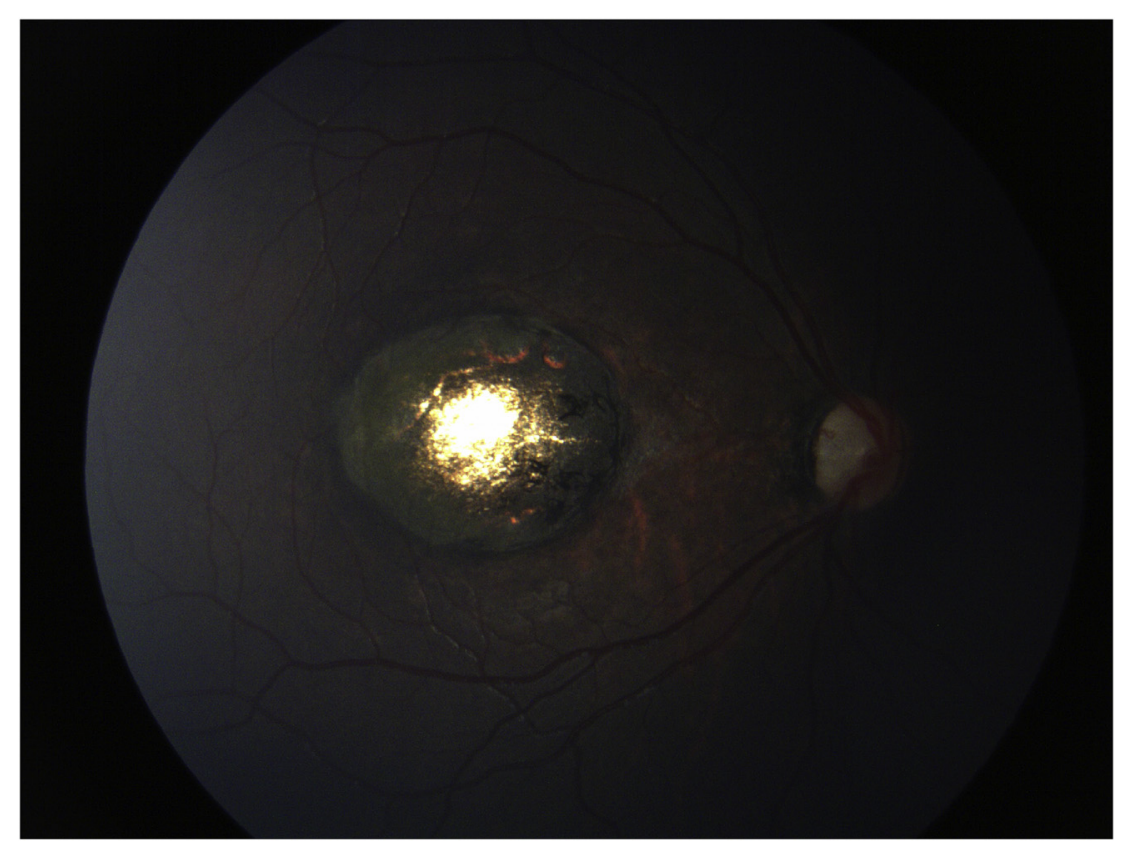

Fig. 4. A wide-angle fundus image (RetCam) of the right eye of an infant with congenital Zika syndrome shows sharply demarcated macular chorioretinal atrophy.

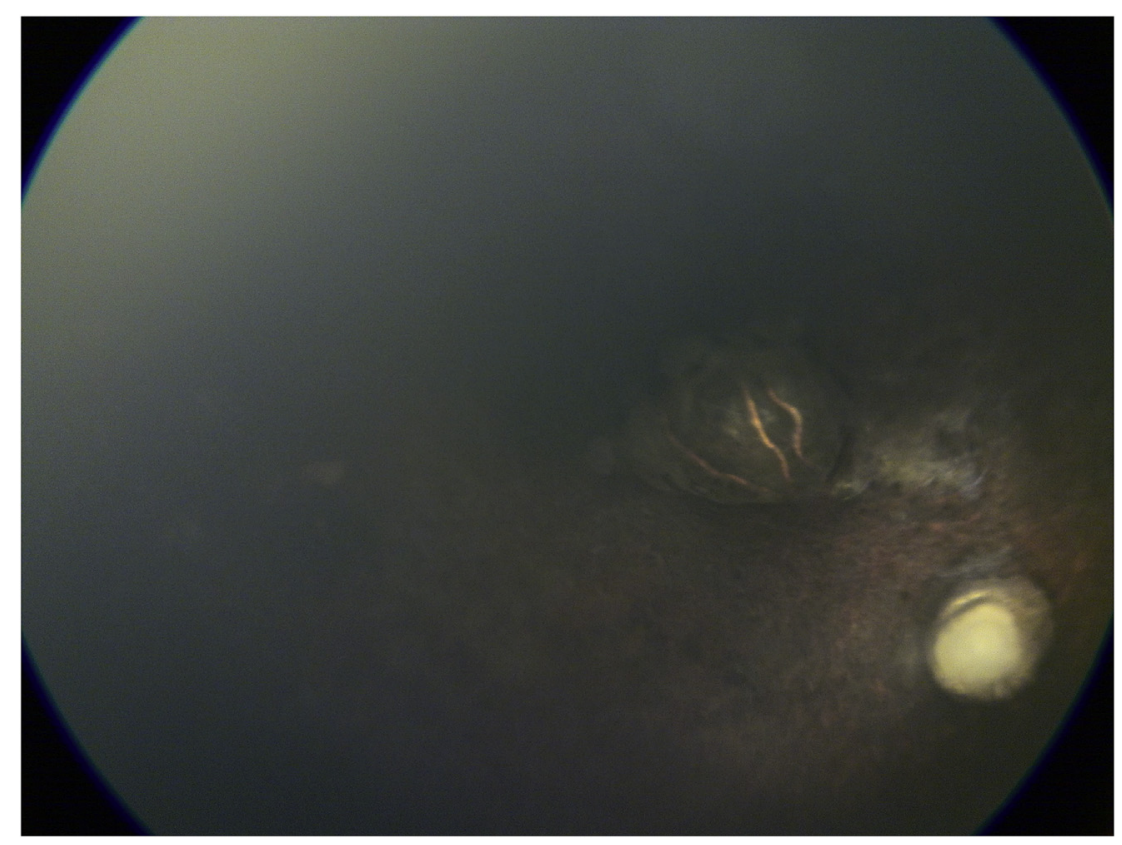

Fig. 5. A wide-angle fundus image (PanoCam) of the right of an infant with congenital Zika syndrome shows optic disc pallor, increased cup-to-disc ratio, gross pigment mottling, and macular chorioretinal atrophy.

fundus findings in both infants were similar to lesion patterns already described (de Paula Freitas et al., 2016; Ventura et al., 2016b, f; Miranda et al., 2016). However, the severity and extent of the chorioretinal atrophic areas seen in the infant from Guarulhos (case 1) only resembled one case from Salvador that was reported previously by de Paula Freitas et al. (2016). The OCT findings reflected the broad range of retinal damage caused by ZIKV.

Zin et al. (2017) evaluated 230 infants from Rio de Janeiro, Rio de Janeiro State, with microcephaly, and 112 who met the inclusion criteria of mothers with RT-PCR positivity for ZIKV infection and underwent ocular examinations (median age, 31 days; range, 0-305 days). Among the 112 infants, $17.9 \%$ had microcephaly, $27.7 \%$ CNS abnormalities (ventriculomegaly, cerebral calcifications, posterior fossa abnormalities, pachygyria, and lissencephaly); and 54.5\% no CNS abnormalities. In this cohort, $21.4 \%$ had abnormal ocular findings. Ocular abnormalities were found in $14(70 \%)$ of 20 infants with microcephaly, two (6.5\%) of 31 with CNS abnormalities without microcephaly and eight $(13.1 \%)$ of 61 without CNS abnormalities. Seven (6.3\%) of 112 had arthrogryposis, ocular abnormalities (optic nerve atrophy, chorioretinal atrophy, pigment mottling, and hemorrhage), microcephaly, and other CNS abnormalities.

Twenty-four (21.4\%) of 112 infants had ocular abnormalities, including microphthalmia (4.2\%), optic nerve abnormalities $(79.2 \%)$, and retinal abnormalities (58.3\%), including focal pigment mottling, chorioretinal atrophy, hemorrhages, and bilateral inferior coloboma. Nystagmus (25\%) also was reported. This study showed that 10 (41.7\%) of 24 eyes had abnormalities without microcephaly in RT-PCR-confirmed cases of ZIKV infection, also supporting that ZIKV can directly 


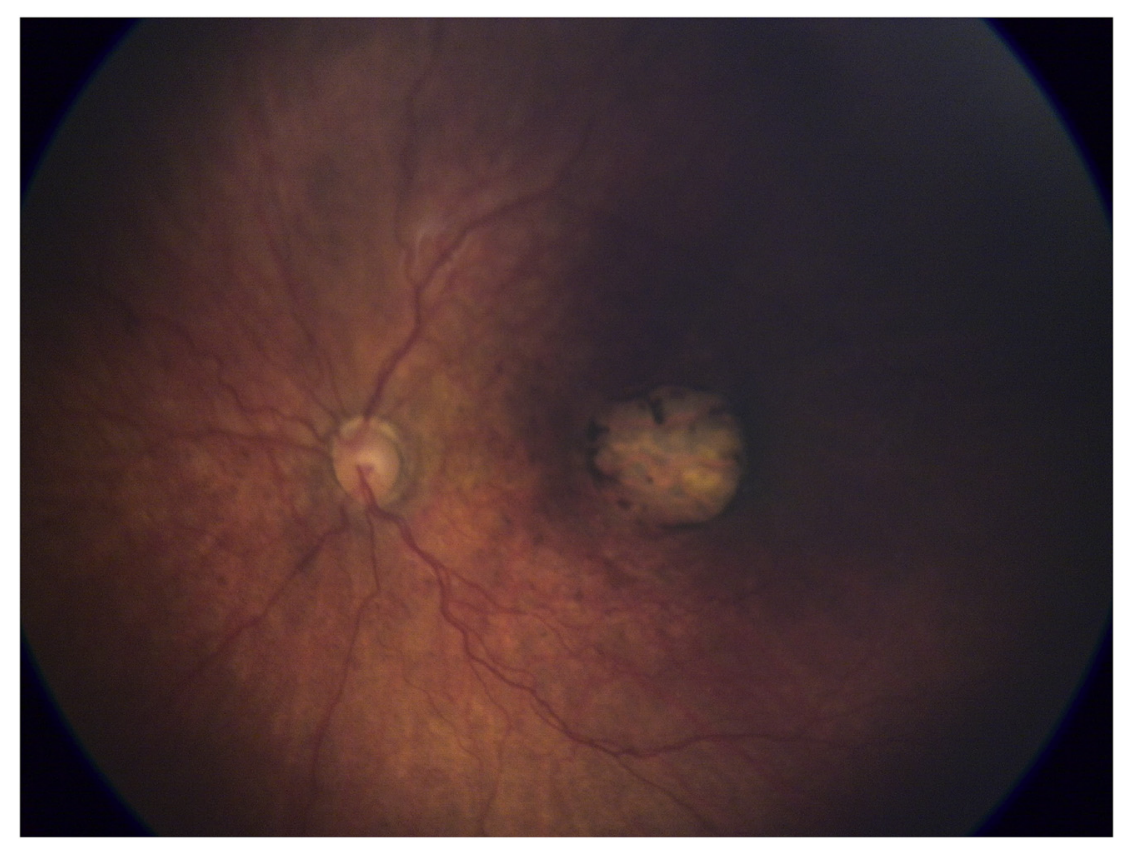

Fig. 6. A wide-angle fundus image (PanoCam) of the left eye of an infant with congenital Zika syndrome shows a roundish macular chorioretinal atrophic lesion with a hyperpigmented halo surrounded by gross pigment mottling.

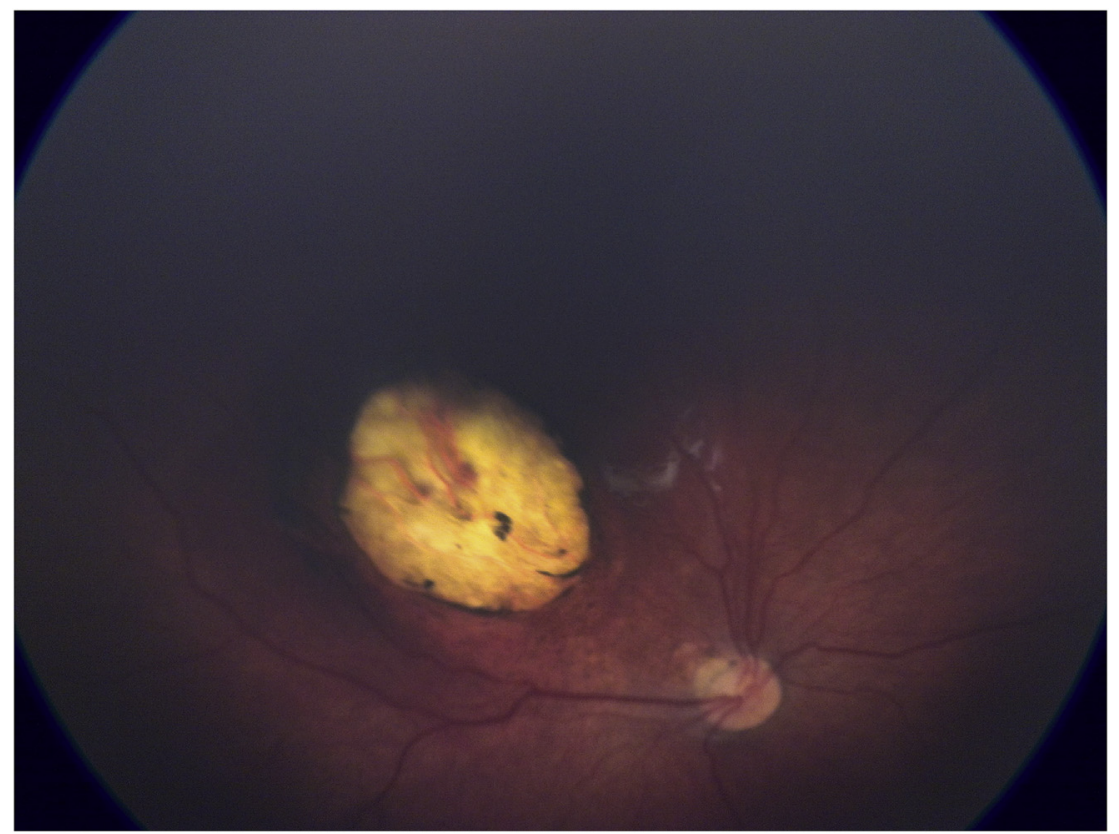

Fig. 7. A wide-angle fundus image (PanoCam) of an infant with congenital Zika syndrome. In the right eye, optic disc hypoplasia, peripapillary atrophy, and a macular chorioretinal atrophic lesion are seen.

cause ocular abnormalities even without microcephaly.

In conclusion, Zin et al. (2017) suggested that ocular abnormalities may be the only initial finding in congenital ZIKV infection. All infants with potential ZIKV exposure should undergo screening ocular examinations regardless of CNS abnormalities, timing of maternal infection during pregnancy, or laboratory confirmation.

\subsection{Ophthalmic manifestations of CZS in Colombia, Venezuela, and the US}

A prospective case series evaluated 43 microcephalic infants with CZS from Maracaibo city in Venezuela and Cúcuta in Colombia (Yepez et al., 2017). Microcephaly was defined as a cephalic circumference of $32 \mathrm{~cm}$ or less at birth. All infants and mothers underwent systemic evaluation and documentation with fundus imaging.

The mean \pm standard deviation (SD) age on the day of the examination was $2.1 \pm 1.5$ months (range, 0.2-6.6 months). All children were born during the ZIKV outbreaks in Colombia and Venezuela, and all mothers were clinically diagnosed with ZIKV infection and reported symptoms (malaise, rash, and arthralgia) during pregnancy. No mothers presented with any ocular findings. Five (12\%) infants had optic disc hypoplasia with the double-ring sign, pallor, and increased cup-todisc ratio. Macular abnormalities included mild-to-severe pigment mottling in 27 infants (63\%) and lacunar maculopathy in three (7\%), defined as diffuse lacunar chorioretinal dysplasia. Eleven (26\%) patients had a combination of lesions in the posterior pole. Five (12\%) infants had congenital glaucoma. The study limitations included the 
retrospective design and absence of specific ZIKV serology in the mothers and infants. In addition, only infants with microcephaly were included, so ocular features might have been overlooked.

In October 2016, Ventura et al. (2016e) described the first travelassociated CZS in the US in a 6-day-old newborn with a known diagnosis of congenital Zika infection confirmed during prenatal screening. The mother had rash, conjunctivitis, and malaise in the first trimester of pregnancy while living in Venezuela. Brain ultrasonography and magnetic resonance imaging showed calcification in the frontal lobe; fundus examination showed a hypopigmented retinal lesion in the left eye.

In the US, Honein et al. (2017) evaluated 442 term pregnancies with laboratory evidence of possible recent ZIKV infection. The authors found 26 fetuses or infants with birth defects, and laboratory evidence of ZIKV infection was found in the mother, placenta, fetus, or infant. Congenital defects related to ZIKV infection during pregnancy included brain abnormalities, neural tube defects, arthrogryposis, clubfoot, congenital hip dysplasia, congenital deafness, and ocular abnormalities. Ocular abnormalities that were considered to be potentially related to ZIKV were microphthalmia/anophthalmia, coloboma, cataract, intraocular calcifications, macular pallor, gross pigmentary mottling, chorioretinal atrophy and scarring, retinal hemorrhage, and optic nerve atrophy. Twenty-two (85\%) of these fetuses or infants had brain abnormalities and/or microcephaly. Among the four patients with congenital alterations without brain abnormalities or microcephaly, one had ocular abnormalities, two encephalocele, and one hearing abnormalities.

\subsection{Glaucoma and CZS}

de Paula Freitas et al. (2017a) reported for the first time a child with CZS and congenital glaucoma in a mother that reported symptoms of acute ZIKV infection during the fourth week of pregnancy. The infant, delivered by caesarian section, weighed $1892 \mathrm{~g}$ at 38 weeks gestation and had severe microcephaly (4.54 SDs below the Intergrowth $21 \mathrm{st}$ standard and more than 2 SDs below the mean for age and sex) (Intergrowth-21st, 2017), bilateral lower extremity arthrogryposis, ventriculomegaly, diffuse parenchymal calcifications, dysgenesis of the corpus callosum, and a simplified gyral pattern.

Chorioretinal atrophy and focal pigmented mottling were found bilaterally as well as optic nerve hypoplasia in the right eye. Serum tested positive for anti-ZIKV IgM antibodies and negative for anti-DENV virus IgM antibodies and other congenital infections. Real-time RT-PCR testing of newborn blood did not detect ZIKV RNA. The infant had persistent tearing, irritability, and photophobia. The right eye was enlarged (Fig. 8), the cornea edematous, and the intraocular pressure (IOP) increased compared to the left eye $(30 \mathrm{mmHg}$ in the right eye; $14 \mathrm{mmHg}$ in the left eye). The left eye was unremarkable. The infant underwent a trabeculectomy in the right eye, which resulted in normalization of the IOP (15 mmHg) and decreased corneal edema, tearing, and photophobia. Real-time RT-PCR did not detect ZIKV-specific RNA in the aqueous humor and vitreous obtained intraoperatively.

Yepez et al. (2017) also described congenital glaucoma in five (12\%) of 43 patients with CZS in two centers in Colombia and Venezuela. All five patients presented with the clinical triad of epiphora, photophobia, and blepharospasm and increased IOP, buphthalmos, corneal enlargement, and corneal clouding at birth. Three patients had Haab's striae. Four patients had a cup-to-disc ratio of 0.7 in both eyes and one patient had 0.8 in both eyes. No patient had anterior uveitis. All patients underwent a combined trabeculotomy and trabeculectomy; one patient also needed IOP-lowering medications.

\section{Risk factors for ophthalmoscopic findings in infants with CZS}

One study identified possible risk factors for ophthalmoscopic findings in infants born with microcephaly who had a clinical and serologic diagnosis of CZS, which provided important scientific

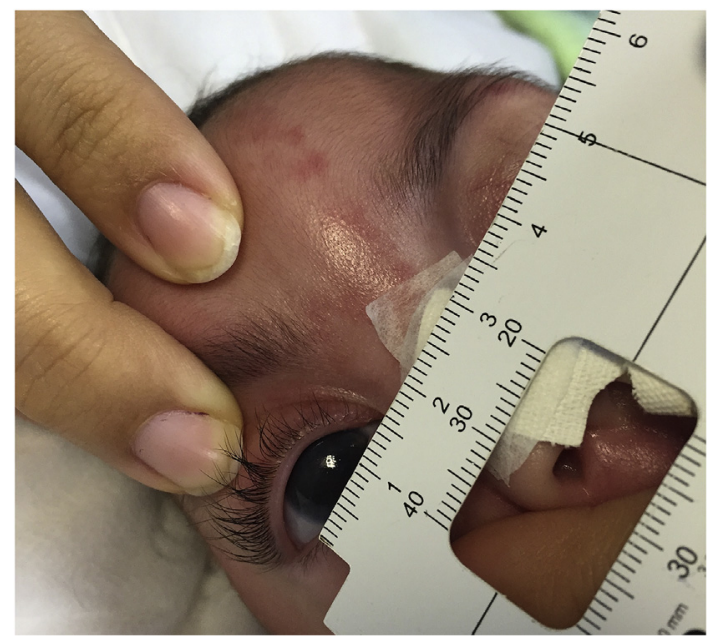

Fig. 8. An enlarged right eye (buphthalmos) typically associated with congenital glaucoma in an infant presenting with congenital Zika syndrome.

contributions (Ventura et al., 2016c).

Forty infants met the inclusion criteria, and 24 (60.0\%) were tested for ZIKV in the CSF using IgM MAC-ELISA as described previously (Martin et al., 2000). All 24 infants that underwent IgM MAC-ELISA had CSF findings positive for ZIKV: 14 (63.6\%) of 22 infants from the group with ophthalmoscopic findings and 10 (55.6\%) of 18 infants from the group without ophthalmoscopic findings. An educational psychologist interviewed all mothers to record pregnancy duration, mode of delivery, and symptoms during pregnancy according to a standardized questionnaire (Ventura et al., 2014).

The mean \pm SD patient age at examination was $2.2 \pm 1.2$ months (range, 0.1-7.3 months); 21 (52.5\%) infants were male. The mean \pm SD maternal age at the time of examination was $25.6 \pm 7.0$ years (range, 16-42 years). At birth, the infants' mean \pm SD cephalic perimeter was $29.5 \pm 1.8 \mathrm{~cm}$ (range, $26-32 \mathrm{~cm}$ ); the mean \pm SD birth weight was $2674 \pm 464.9 \mathrm{~g}$ (range, 1690-3665 g). Thirty (75.0\%) patients underwent CT scanning, of whom 29 (96.7\%) had cerebral calcifications. Twenty-eight $(70.0 \%)$ infants were born at term, 11 (27.5\%) pre-term, and one $(2.5 \%)$ post-term. One caregiver from each group did not provide the mode of delivery. Twenty-one (55.3\%) of 38 mothers reported undergoing a cesarean delivery.

Analysis of the pregnancy durations, mode of deliveries, and presence or absence of ophthalmoscopic alterations showed no significant differences. There were also no significant differences between the groups with and without ocular findings in the mean \pm SD maternal age at examination, infants' mean \pm SD age at examination, male:female ratio, and birth weight. There was a difference between the groups (with or without fundus alterations) in the cephalic perimeter at birth. Comparison of the specific symptoms reported by mothers of infants with fundus abnormalities and those with normal ocular examinations showed similar incidence rates in both groups $(P>0.05$ for all comparisons). However, the groups differed significantly $(P=0.04)$ regarding the time of symptom occurrence, i.e., $10(71.4 \%)$ of 14 mothers with infants with ocular findings reported symptoms during the first trimester, whereas eight (61.5\%) of 13 mothers with infants with a normal ocular examination had symptoms during the second trimester.

Macular alterations were seen more frequently and were severe in infants whose mothers reported symptoms during the first trimester. No mothers reported conjunctivitis or ocular symptoms during pregnancy. All had normal ocular examinations, except for one mother with a pale optic disc in the right eye; however, she reported decreased vision before pregnancy.

Fundus alterations were seen in $37(46.3 \%)$ eyes of $22(55.0 \%)$ 
infants, and they were bilateral in 15 (68.2\%). In five (22.7\%) infants, only the optic nerve was affected, in seven $(31.8 \%)$ only the macula, and in $10(45.5 \%)$ both structures. The optic nerve abnormalities included the double-ring sign, optic disc pallor, and increased cup-to-disc ratio. Macular abnormalities were present in 24 (30.0\%) eyes of 17 $(42.5 \%)$ infants and were unilateral in $10(58.8 \%)$ infants. The macular abnormalities included foveal reflex loss, mild-to-gross pigment mottling, and sharply demarcated circular areas of chorioretinal atrophy.

The mean \pm SD axial length was $18.5 \pm 0.9 \mathrm{~mm}$ (range, 16.8-21 mm) and did not differ significantly between the group with or without ocular abnormalities. In the eyes with macular alterations, ocular ultrasonography did not detect posterior coloboma. The retina and choroid were attached in all eyes, and no signs of uveitis or ocular calcifications were detected. No anterior coloboma was identified during the ocular examination.

A study limitation was the absence of specific serology in all infants to confirm the ZIKV infection. Another limitation concerned the data collected regarding the mothers' symptoms during pregnancy. All data analyzed were based on reports by the mothers. Finally, only infants with microcephaly were included because there was no evidence at the time of publication that infants with CZS could present without microcephaly at birth.

\section{OCT findings in infants with CZS}

OCT findings in children with CZS were described in children from Recife (Ventura et al., 2016f; Campos et al., 2016) and São Paulo (de Oliveira Dias et al., 2017) cities, Brazil. A study in Recife described for the first time the OCT findings in infants with positive retinal findings and CZS (Ventura et al., 2016f). This study evaluated the affected retinal layers in eight infants (five girls, three boys; mean age, $4.1 \pm 0.7$ months; range, 3.0-5.1 months) with CZS and retinal abnormalities using OCT. After February 2016, serologic testing for ZIKV was available in Brazil, and the CSF samples of all other infants except one from Recife were tested for the ZIKV infection using the IgM antibody-capture MAC-ELISA.

OCT imaging was obtained using standard OCT equipment, as a portable OCT instrument was unavailable. The optic nerve was not assessed by OCT in this study. OCT scanning was performed in nine $(82 \%)$ affected eyes and in the unaffected eye of one patient, because of the difficulty performing this imaging modality in both eyes. Eleven $(69 \%)$ of the 16 eyes had retinal changes that included chorioretinal atrophy in 10 (63\%) eyes and pigment mottling in seven (44\%) eyes. The OCT findings in the nine affected eyes included discontinuation of the ellipsoid zone and hyperreflectivity underlying the RPE in the nine eyes $(100 \%)$ evaluated; retinal thinning in eight (89\%) eyes; choroidal thinning in seven (78\%) eyes; macular pseudocoloboma in four $(44 \%)$ eyes; a possible cleft in three (33\%) eyes; and hyperreflective dots in the inner retinal layers in one (11\%) eye (Fig. 2).

Campos et al. (2016) also described the OCT findings in a 1-month old microcephalic infant with macular atrophy and presumed CZS; OCT showed atrophy of the outer retinal layers and choriocapillaris, including the outer nuclear layer and ellipsoid zone, associated with RPE hyperreflectivity. Such findings resemble those reported by Ventura et al. (2016f) and de Oliveira Dias et al. (2017) who described a similar pattern of retinal and choroidal complete excavated chorioretinal atrophy with a pseudocoloboma in one infants who presented with macular chorioretinal atrophy.

Standard OCT devices were used to obtain a better understanding of the effect of ZIKV on the retina, RPE, and choroid. Despite the unavailability of portable devices, the images obtained in all three studies were of sufficient quality to perceive the details of the affected retinal layers. The main OCT findings in these infants included severe neurosensory retinal thinning with discontinuation of the ellipsoid zone, choroidal thinning, and hyperreflectivity under the atrophic RPE. Although these OCT findings provided knowledge regarding the lesion severity observed clinically in these patients with CZS, they are not pathognomonic of this disease. Cytomegalovirus retinitis and toxoplasmosis retinochoroiditis may present with similar OCT findings, including chorioretinal thinning and discontinuation of the ellipsoid zone (Garg et al., 2009; Goldenberg et al., 2013; Sun et al., 2012). The hyperreflectivity seen under the RPE in most of these eyes also is seen in other retinal diseases with severe RPE involvement, which is simply the signal's transmission through atrophic tissue.

The pseudocoloboma observed in some eyes corresponded to the severe excavated chorioretinal atrophy observed clinically. Although they simulate macular coloboma, ocular ultrasonography ruled out this possibility in all eyes. These colobomatous-like lesions also have been described in scarred congenital toxoplasmosis lesions and congenital macular coloboma (Garg et al., 2009; Goldenberg et al., 2013; Sun et al., 2012).

Another interesting OCT finding in one infant was hyperreflective dots in the inner retinal layers, which was speculated to correspond to the retinal pigment mottling observed in the fundus photographs (Ventura et al., 2016f); however, they also could have been related to signal distortion. These OCT findings suggested that neurotropism of ZIKV might result in significant necrosis of the retinal tissue. The study limitations included the small sample size, lack of newborn cooperation, inability to document bilateral disease systematically, lack of a point-to-point correlation between OCT and fundus findings, and no possibility of CSF testing for ZIKV in one patient.

A study was performed to better understand the microstructural retinal changes in CZS (Aleman et al., 2017). Eight patients with CZS and eight individuals with cobalamin $\mathrm{C}$ (cblC) deficiency have been previously examined by OCT (Ventura et al., 2016f; Bonafede et al., 2015). Similar OCT findings in both diseases indicated that retinal regions without chorioretinal atrophy had GCL loss on OCT that was disproportionately more severe than coexisting changes in both inner retinal layers and photoreceptors. The severity of GCL thinning associated with the spared outer nuclear layer was almost identical to that seen in cblC deficiency (Fig. 2), suggesting a similar pathophysiology in both diseases.

\section{Visual assessment in children with CZS}

Ventura et al. (2017a) described visual impairment associated with ocular and neurologic abnormalities in infants with CZS. All children were born in Pernambuco, Brazil, between May and December 2015, and infants with neuroimaging or neurologic abnormalities detected at birth and a positive IgM anti-Zika MAC-ELISA on CSF were included.

Monocular and binocular VAs were assessed using the Teller Acuity Cards II. Strabismus was evaluated using the Krimsky test, and the presence of nystagmus was recorded. Light perception, response to the human face, shift of gaze for cortical function evaluation, and the Hiding Heidi contrast test were tested. Cycloplegic refraction and bilateral retinal imaging were performed in all children. All children underwent neuroimaging and neurodevelopmental clinical evaluation.

Thirty-two infants were included, with a mean \pm SD age of $5.7 \pm 0.9$ months (range, 4.0-7.0 months) during the ophthalmologic evaluation. Nystagmus was identified in $28 \%$ of infants and strabismus in $75 \%$. All children had an abnormality in at least one of the visual function and visual developmental milestone tests. Visual impairment was detected in $32(100 \%)$ infants, and retinal and/or optic nerve findings in $14(44 \%)$ patients. There was no significant difference between the patients with and without ocular findings. CNS abnormalities were detected in all infants. It is important that three infants did not present with microcephaly at birth; however, it developed later, as van der Linden et al. (2016b) reported.

This study showed that, regardless of fundus involvement, all infants presented with visual impairment, suggesting that visual impairment is mostly related to CNS abnormalities and that cerebral abnormalities are the most common cause of visual impairment in 
children with CZS. This study emphasized the need for healthcare professionals to recognize that infants with CZS have abnormal visual function, regardless of the presence of microcephaly at birth or even no fundus abnormalities.

Another study assessed the visual response to correction of refractive errors and hypoaccommodation in children with CZS (Ventura et al., 2017a,b). Children were prescribed full correction if they met pre-established criteria for refractive error, strabismus, accommodative dysfunction, and/or low vision. Visual responses to the Lea Grating Test at $30 \mathrm{~cm}$, with and without eyeglasses, were measured on day 1 of glasses wear. Sixty children (mean age at evaluation, $11.5 \pm 1.1$ months; range, 9.0-16.0 months) were included in this study. Visual responses were abnormal even with glasses, but immediate improvement in binocular vision was found in $62 \%$ of the children and in $62.2 \%$ of the eyes. Significant differences were seen in the refractive status of the children over 3 months (emmetropia, hyperopia, myopia, and astigmatism $\leq-2.00$ cylinder diopter). This study suggested that eyeglasses can improve VA in children with CZS. Significant changes in the infants' refractive status over time require periodic updates.

\section{Public health implications, scientific relevance, and pandemic potential}

ZIKV epidemics around the world have become a public health emergency. Surveillance activities for ZIKV in areas where transmission occurs focus on recording case numbers, complications of the infection, and vectors. The objectives of the surveillance for human cases are monitoring of the geographic distribution and temporal trend of infection, identification of infection-related complications, identification of non-vector borne routes of transmission, and monitoring of the effectiveness of containment measures (WHO, 2016d).

In countries in which the etiologic agent (virus) may proliferate and the local transmitter (biologic vector) is endemic, the key surveillance objectives are to ascertain imported cases and undertake vector monitoring. In countries where there is no chance of local transmission by vectors, the focus is on identifying imported cases. Travelers exposed to poverty and poor sanitary conditions seem to be the key points for the global spread of ZIKV (WHO, 2016d). When returning home to countries where competent vectors are present, travelers can introduce ZIKV into new areas, thereby also providing a source for propagation and circulation of infection among the local population in risk countries for propagation of mosquitoes (Bogoch et al., 2016).

In March 2017, country classifications for ZIKV epidemiology were modified by a working group formed by the WHO, CDC, and the ECDC to achieve greater agreement (Leder et al., 2017). This joint effort resulted in revisions leading to four main categories: category 1 , new or re-introduction and ongoing transmission; category 2, past or ongoing transmission but not in the new or re-introductory phase; category 3, interrupted transmission with potential for future transmission; and category 4, competent vector exists but no known past or current transmission.

Characteristics of ZIKV transmission often can be best determined in travelers returning from endemic areas, for which the exposure period may be more easily determined than among local populations. Sexual transmission is best assessed in non-endemic settings where there are no competent mosquito vectors; notably, the first published detection of sexual transmission occurred in a traveler from Africa (Foy et al., 2011). These data underpin current international guidelines recommendations for avoidance of pregnancy for at least 6 months after potential exposure for men and at least 8 weeks for women (Leder et al., 2017).

In Brazil, according to an "Epidemiological Week" (EW) the Ministry of Health reported 13,835 suspected cases of changes in growth and development possibly related to ZIKV infection and other infectious etiologies, of which 3211 (23.2\%) remained under investigation in EW 20/2017. Of the total cases, 5892 (42.6\%) were discarded, 2753 (19.9\%) were treated, and 141 (1.0\%) were classified as likely related to congenital infection during gestation. In addition, $1838(13.3 \%)$ cases were excluded because they did not meet the current case definitions. Among the cases reported, 1433 (52.1\%) were receiving care in childcare, $1110(40.3 \%)$ in early cognitive stimulation, and 1524 (55.4\%) in specialized care services (Ministério da Saúde do Brasil, 2017).

Disease control methods available against ZIKV are limited. There are no licensed vaccines against the virus or anti-viral drugs to reduce the viremic period during which a competent vector (Aedes species) with hematophagic behavior may amplify the disease. Mice studies showed that ZIKV envelope glycoproteins have been identified as candidates for vaccine development, as they have been correlated to the induction of potent ZIKV-specific neutralizing antibodies (Zhao et al., 2016). A ZIKV vaccine has been studied, and possible ways include developing inactivated, recombinant live-attenuated viruses, protein subunit vaccines, virus-like particles, RNA, and DNA vaccines (Salvo et al., 2018). In addition, it was reported in a murine model that neutralizing human antibody can protect mice against maternal-fetal transmission, infection and disease (Sapparapu et al., 2016).

Therefore, vector control measures are crucial, and reducing contact between hosts and vectors forms the basis of disease control strategies worldwide. Two broad types of complementary vector control strategies can be applied: first, individuals must take personal responsibility for avoiding mosquito bites, and second, government and non-government organizations must implement vector surveillance and control programs at global, national, and local levels (Saiz et al., 2017).

Many uncertainties in ZIKV epidemiology, transmission, and risk of adverse outcomes remain, and consensus on diagnostic and definition issues is needed. Overall, the global risk assessment is unchanged. ZIKV continues to spread geographically to areas where competent vectors are present. Although a decline in cases of ZIKV infection has been reported in some countries, or in some parts of countries, vigilance needs to remain high.

\section{Conclusions}

1. Approximately $29 \%-70 \%$ of infants with CZS and microcephaly have associated severe ocular abnormalities. The ophthalmoscopic changes more frequently reported are focal pigment mottling and chorioretinal atrophy with a predilection for the macula as well as optic disc abnormalities. Congenital glaucoma can also be seen in infants with CZS.

2. OCT imaging in CZS has demonstrated severe involvement of the neurosensory retina, including changes in the inner and outer retinal layers as well as in the choroid. There is a peculiar predilection for inner retinal thinning in CZS, particularly GCL loss.

3. Fundus abnormalities in infants with CZS were associated with smaller cephalic diameters at birth and were more frequent in infants whose mothers reported symptoms during the first trimester of their pregnancies.

4. Evidence supports the potential for a rapid spread of this devastating disease (CZS) as well as for heterogeneous ocular manifestations, including macular atrophy, optic nerve abnormalities and congenital glaucoma.

5. Vaccine development, vector control, avoidance of endemic regions by pregnant women and/or the use insect repellents are recommended preventive measures.

6. Microcephalic newborns should undergo ophthalmic evaluations due to the potential abnormalities in the fundus of CZS patients. Multidisciplinary teams are needed for early cognitive and visual stimulation of newborns, and additional studies with longer followup periods are needed.

7. We hypothesize that the retinal abnormalities in CZS mimic CNS changes and result from the loss of specific neuronal progenitors in utero, predominatly, retinal ganglion cells, which may result in foveal maldevelopment, secondary central chorioretinal atrophy and 
optic nerve abnormalities.

\section{Future directions}

To control the disease spread and ramifications, new strategies are being adopted worldwide. The Pan American Health Organization (PAHO)/WHO have re-emphasized surveillance recommendations and prevention control measures such as actions to control the vector ( $A$. aegypti) and encouragement of pregnant women to use mosquito repellents, and are supporting research to develop antiviral therapy and vaccines against ZIKV (PAHO, 2016; WHO, 2017a). The CDC also recommended that pregnant women not travel to countries with ZIKV cases (CDC, 2016). The CDC also recommended that men who travel to areas with active ZIKV infection should abstain from sexual intercourse or use condoms for at least 6 months.

The knowledge of ocular involvement in CZS is based on case series from many researchers including the Zika Virus Study Group. We propose performing ophthalmologic evaluations not only of newborns with clinical and/or laboratory evidence of ZIKV but also of apparently healthy children whose mothers presented with laboratory evidence of ZIKV infection during pregnancy or even suspicious cases in endemic areas. These examinations are important both to obtain a better understanding of the disease and to plan visual rehabilitation strategies for improvement of the cognitive aspects.

The exact timelines of ocular examinations remain unknown. Prospective and multicenter studies will provide important data on the natural disease course, which will contribute to the establishment of reliable guidelines related to diagnosis, treatment, and follow-up for rehabilitation and ocular care of newborns with CZS.

\section{Appendix. Zika Virus Study Group members}

Andréa Zin, MD, PhD - Clinical Research Unit, Fernandes Figueira Institute, Oswaldo Cruz Foundation, Rio de Janeiro, Brazil.

Adriana L Gois, MD - Altino Ventura Foundation, Recife, Pernambuco, Brazil.

Albert Icksang Ko, PhD - Gonçalo Moniz Research Centre, Oswaldo Cruz Foundation, Salvador, Brazil; Department of Epidemiology of Microbial Diseases, Yale School of Public Health, New Haven, Connecticut.

Audina Berrocal, MD - Bascom Palmer Eye Institute Miller School of Medicine.

Bruna Ventura, MD, PhD - Altino Ventura Foundation, Recife, Pernambuco, Brazil; HOPE Eye Hospital, Recife, Pernambuco, Brazil; Vision Institute, Department of Ophthalmology, Paulista Medical School, Federal University of São Paulo, São Paulo, Brazil. Bruno de Paula Freitas, MD - Department of Ophthalmology, Roberto Santos General Hospital, Salvador, Brazil; Vision Institute, Department of Ophthalmology, Paulista Medical School, Federal University of São Paulo, São Paulo, Brazil.

Camila V. Ventura, MD, PhD - Altino Ventura Foundation, Recife, Pernambuco, Brazil; HOPE Eye Hospital, Recife, Pernambuco, Brazil; Vision Institute, Department of Ophthalmology, Paulista Medical School, Federal University of São Paulo, São Paulo, Brazil. Eveline B. Araujo, MD. Altino Ventura Foundation, Recife, Pernambuco, Brazil; HOPE Eye Hospital, Recife, Pernambuco, Brazil.

Gielson A. Sacramento, MD - Gonçalo Moniz Research Centre, Oswaldo Cruz Foundation, Salvador, Brazil.

João Rafael de Oliveira Dias, MD, PhD. Vision Institute, Department of Ophthalmology, Paulista Medical School, Federal University of São Paulo, São Paulo, Brazil.

Juliana Prazeres, MD. Vision Institute, Department of Ophthalmology, Paulista Medical School, Federal University of São Paulo, São Paulo, Brazil.

Liana O. Ventura, MD, PhD - Altino Ventura Foundation, Recife,
Pernambuco, Brazil; HOPE Eye Hospital, Recife, Pernambuco, Brazil; Vision Institute, Department of Ophthalmology, Paulista Medical School, Federal University of São Paulo, São Paulo, Brazil. Maria Angela W. Rocha, MD - Oswaldo Cruz University Hospital (HUOC), Recife, Pernambuco, Brazil.

Maria Durce C. G. Carvalho, MD - Oswaldo Cruz University Hospital (HUOC), Recife, Pernambuco, Brazil.

Mauricio Maia, MD, PhD. Vision Institute, Department of Ophthalmology, Paulista Medical School, Federal University of São Paulo, São Paulo, Brazil; Brazilian Institute of Fight Against Blindness, Assis and Presidente Prudente, São Paulo, Brazil.

Miguel Burnier, MD, PhD. Henry Witelson Ocular Pathology Laboratory and Clinical Research \& Training of the MacGill University Health Centre, Montreal, Canada.

Nilva S. B. de Moraes, MD, PhD. Vision Institute, Department of Ophthalmology, Paulista Medical School, Federal University of São Paulo, São Paulo, Brazil.

Regina Ramos, MD - Oswaldo Cruz University Hospital (HUOC), Recife, Pernambuco, Brazil.

Robert Nussenblatt, $\mathrm{MD}, \mathrm{PhD}$ (in memoriam). Laboratory of Immunology at the National Eye Institute (NEI) and National Institute of Health (NIH), Bethesda.

Vasco Bravo-Filho, MD. Altino Ventura Foundation, Recife, Pernambuco, Brazil.

Vanessa van der Linden, MD - Hospital Barão de Lucena, Recife, Pernambuco, Brazil.

Rubens Belfort Jr., MD, PhD - Vision Institute, Department of Ophthalmology, Paulista Medical School, Federal University of São Paulo, São Paulo, Brazil.

Tomas Alleman, MD, PhD - Scheie Eye Institute at the Perelman Centre for Advanced Medicine, Perelman School of Medicine, Department of Ophthalmology, University of Pennsylvania, Philadelphia.

\section{References}

Aagaard, K.M., Lahon, A., Suter, M.A., Arya, R.P., Seferovic, M.D., Vogt, M.B., Hu, M., Stossi, F., Mancini, M.A., Harris, R.A., Kahr, M., Eppes, C., Rac, M., Belfort, M.A., Park, C.S., Lacorazza, D., Rico-Hesse, R., 2017. Primary human placental trophoblasts are permissive for Zika vírus (ZIKV) replication. 2017. Sci. Rep. 7, 41389.

Adibi, J.J., Marques Jr., E.T., Cartus, A., Beigi, R.H., 2016. Teratogenic effects of the Zika virus and the role of the placenta. Lancet 387, 1587-1590.

Akoua-Koffi, C., Diarrassouba, S., Benie, V.B., Ngbichi, J.M., Bozoua, T., Bosson, A. Akran, V., Carnevale, P., Ehouman, A., 2001. Investigation surrounding a fatal case of yellow fever in Cote d'Ivoire in 1999. Bull. Soc. Pathol. Exot. 94, 227-230.

Aleman, T.S., Ventura, C.V., Cavalcanti, M.M., Serrano, L.W., Traband, A., Nti, A.A., Gois, A.L., Bravo-Filho, V., Martins, T.T., Nichols, C.W., Maia, M., Belfort Jr., R., 2017. Quantitative assessment of microstructural changes of the retina in infants with congenital Zika syndrome. JAMA Ophthalmology 135, 1069-1076.

Alpert, S., Fergerson, J., Noël, L., 2003. Intrauterine West Nile virus: ocular and systemic findings. Am J Ophthalmol. 136, 733-735.

Alpuche-Lazcano, S.P., McCullogh, C.R., Del Corpo, O., Rance, E., Scarborough, R.J., Mouland, A.J., Sagan, S.M., Teixeira, M.M., Gatignol, A., 2018. Higher cytopatic effects of a Zika virus Brazilian isolate from Bahia compared to a Canadian-imported Thai strain. Viruses 2018, 10 pii: E53.

Althouse, B.M., Vasilakis, N., Sall, A.A., Diallo, M., Weaver, S.C., Hanley, K.A., 2016. Potential for zika virus to establish a sylvatic transmission cycle in the Americas. PLoS Neglected Trop. Dis. 10.

Alvarado, M.G., Schwartz, D.A., 2017. Zika virus infection in pregnancy, microcephaly, and maternal and fetal health: what we think, what we know, and what we think we know. Arch. Pathol. Lab Med. 141, 26-32.

Aubry, M., Teissier, A., Huart, M., Merceron, S., Vanhomwegen, J., Roche, C., Vial, A.L., Teururai, S., Sicard, S., Paulous, S., Desprès, P., Manuguerra, J.C., Mallet, H.P., Musso, D., Deparis, X., Cao-Lormeau, V.M., 2017. Zika virus seroprevalence, French Polynesia, 2014-2015. Emerg. Infect. Dis. 23, 669-672.

Barjas-Castro, M.L., Angerami, R.N., Cunha, M.S., Suzuki, A., Nogueira, J.S., Rocco, I.M., Maeda, A.Y., Vasami, F.G., Katz, G., Boin, I.F., Stucchi, R.S., Resende, M.R., Esposito, D.L., de Souza, R.P., da Fonseca, B.A., Addas-Carvalho, M., 2016. Probable transfusion-transmitted Zika virus in Brazil. Transfusion 56, 1684-1688.

Berthet, N., Nakouné, E., Kamgang, B., Selekon, B., Descorps-Declère, S., Gessain, A., Manuguerra, J.C., Kazanji, M., 2014. Molecular characterization of three Zika flaviviruses obtained from sylvatic mosquitoes in the Central African Republic. Vector Borne Zoonotic Dis. 14, 862-865.

Besnard, M., Eyrolle-Guignot, D., Guillemette-Artur, P., Lastère, S., Bost-Bezeaud, F., Marcelis, L., Abadie, V., Garel, C., Moutard, M.L., Jouannic, J.M., Rozenberg, F., 
Leparc-Goffart, I., Mallet, H.P., 2016. Congenital cerebral malformations and dysfunction in fetuses and newborns following the 2013 and 2014 Zika vírus epidemic in French Polynesia. Euro Surveill. 21.

Bingham, A.M., Cone, M., Mock, V., Heberlein-Larson, L., Stanek, D., Blackmore, C., Likos, A., 2016. Comparison of test results for Zika virus RNA in urine, serum, and saliva specimens from persons with travel-associated Zika virus disease-Florida, 2016. MMWR Morb. Mortal. Wkly. Rep. 65, 475-478.

Bogoch, I.I., Brady, O.J., Kraemer, M.U.G., German, M., Creatore, M.I., Brent, S., Watts, A.G., Hay, S.I., Kulkarni, M.A., Brownstein, J.S., Khan, K., 2016. Potential for Zika virus introduction and transmission in resource-limited countries in Africa and the Asia-Pacific region: a modelling study. Lancet Infect. Dis. 16, 1237-1245.

Bonafede, L., Ficicioglu, C.H., Serrano, L., Han, G., Morgan, J.I., Mills, M.D., Forbes, B.J., Davidson, S.L., Binenbaum, G., Kaplan, P.B., Nichols, C.W., Verloo, P., Leroy, B.P. Maguire, A.M., Aleman, T.S., 2015. Cobalamin C deficiency shows a rapidly progressing maculopathy with severe photoreceptor and ganglion cell loss. Invest. Ophthalmol. Vis. Sci. 56, 7875-7887.

Bonaldo, M.C., Ribeiro, I.P., Lima, N.S., Dos Santos, A.A., Menezes, L.S., da Cruz, S.O., de Mello, I.S., Furtado, N.D., de Moura, E.E., Damasceno, L., da Silva, K.A., de Castro, M.G., Gerber, A.L., de Almeida, L.G., Lourenço-de-Oliveira, R., Vasconcelos, A.T., Brasil, P., 2016. Isolation on infective zika virus from urine and saliva of patients in Brazil. PLoS Neglected Trop. Dis. 10 e0004816.

Brasil, P., Pereira Jr., J.P., Moreira, M.E., Ribeiro Nogueira, R.M., Damasceno, L., Wakimoto, M., Rabello, R.S., Valderramos, S.G., Halai, U.A., Salles, T.S., Zin, A.A., Horovitz, D., Daltro, P., Boechat, M., Raja Gabaglia, C., Carvalho de Sequeira, P., Pilotto, J.H., Medialdea-Carrera, R., Cotrim da Cunha, D., Abreu de Carvalho, L.M., Pone, M., Machado Siqueira, A., Calvet, G.A., Rodrigues Baião, A.E., Neves, E.S., Nassar de Carvalho, P.R., Hasue, R.H., Marschik, P.B., Einspieler, C., Janzen, C., Cherry, J.D., Bispo de Filippis, A.M., Nielsen-Saines, K., 2016. Zika Virus Infection in Pregnant Women in Rio de Janeiro. N. Engl. J. Med. 375, 2321-2334.

Buechler, C.R., Bailey, A.L., Weiler, A.M., Barry, G.L., Breitbach, M.E., Stewart, L.M., Jasinska, A.J., Freimer, N.B., Apetrei, C., Phillips-Conroy, J.E., Jolly, C.J., Rogers, J., Friedrich, T.C., O'Connor, D.H., 2017. Seroprevalence of zika virus in wild african Green monkeys and baboons. mSphere 2.

Bueno, M.G., Martinez, N., Abdalla, L., Duarte Dos Santos, C.N., Chame, M., 2016. Animals in the zika virus life cycle: what to expect from megadiverse Latin American countries. PLoS Neglected Trop. Dis. 10.

Busch, M.P., Kleinman, S.H., Tobler, L.H., Kamel, H.T., Norris, P.J., Walsh, I., Matud, J.L., Prince, H.E., Lanciotti, R.S., Wright, D.J., Linnen, J.M., Caglioti, S., 2008. Virus and antibody dynamics in acute West Nile virus infection. J. Infect. Dis. 198, 984-993.

Caires-Júnior, L.C., Goulart, E., Melo, U.S., Araujo, B.S.H., Alvizi, L., Soares-Schanoski, A., de Oliveira, D.F., Kobayashi, G.S., Griesi-Oliveira, K., Musso, C.M., Amaral, M.S., da Silva, L.F., Astray, R.M., Suárez-Patiño, S.F., Ventini, D.C., Gomes da Silva, S., Yamamoto, G.L., Ezquina, S., Naslavsky, M.S., Telles-Silva, K.A., Weinmann, K., van der Linden, V., van der Linden, H., de Oliveira, J.M.R., Arrais, N.R.M., Melo, A., Figueiredo, T., Santos, S., Meira, J.C.G., Passos, S.D., de Almeida, R.P., Bispo, A.J.B., Cavalheiro, E.A., Kalil, J., Cunha-Neto, E., Nakaya, H., Andreata-Santos, R., de Souza Ferreira, L.C., Verjovski-Almeida, S., Ho, P.L., Passos-Bueno, M.R., Zatz, M., 2018. Discordant congenital Zika syndrome twins show differential in vitro viral susceptibility of neural progenitor cells. Nat. Commun. 9, 475.

Campos, G.S., Bandeira, A.C., Sardi, S.I., 2015. Zika virus outbreak, Bahia, Brazil. Emerg. Infect. Dis. 21, 1885-1886.

Campos, A.G., de, M., Lira, R.P.C., Arantes, T.E.F., 2016. Optical coherence tomography of macular atrophy associated with microcephaly and presumed intrauterine Zika virus infection. 79, 400-401.

Cao-Lormeau, V.M., Roche, C., Teissier, A., Robin, E., Berry, A.L., Mallet, H.P., Sall, A.A., Musso, D., 2014. Zika virus, French Polynesia, South Pacific, 2013. Emerg. Infect. Dis. 20, 1085-1086.

Cao-Lormeau, V.M., Blake, A., Mons, S., Lastere, S., Roche, C., Vanhomwegen, J., Dub, T., Baudouin, L., Teissier, A., Larre, P., Vial, A.L., Decam, C., Choumet, V., Halstead, S.K., Willison, H.J., Musset, L., Manuguerra, J.C., Despres, P., Fournier, E., Mallet, H.P., Musso, D., Fontanet, A., Neil, J., Ghawché, F., 2016. Guillain-Barré Syndrome outbreak caused by Zika vírus infection in French Polynesia. Lancet 387, 1531-1539.

Centers for Diasease Control and Prevention, 2017. Morbidity and Mortality Week Report (MMWR). Vital Signs: Update on Zika Virus-associated Birth Defects and Evaluation of All U.S. Infants with Congenital Zika Virus Exposure - U.S. Zika Pregnancy Registry, 2016. Available at:. . https://www.cdc.gov/mmwr/volumes/66/wr/ mm6613e1.htm?s_cid = mm6613e1_w (Accessed March 30, 2018).

Centers for Disease Control and Prevention, 2016. C.f.D.C.a.P.-. Zika Virus. Centers for Diseases Control and Prevention. Zika Virus Disease in the United States, 2015-2017. https://www.cdc.gov/zika/reporting/case-counts.html (Accessed March 30 2018).

Centers for Disease Control and Prevention, 2018. Zika Cases in the United States. Available at: https://www.cdc.gov/zika/reporting/case-counts.html (Accessed March 5, 2018).

Centers for Disease Control and Prevention, 2014. Zika Virus - Transmission and Risks. CDC Available at: https://www.cdc.gov/zika/transmission/index.html Accessed 4 October 2017.

Clark, D.H., Casals, J., 1958. Techniques for hemagglutination and hemagglutinationinhibition with arthropod-borne viruses. Am. J. Trop. Med. Hyg. 7, 561-573.

Collins, M.H., McGowan, E., Jadi, R., Young, E., Lopez, C.A., Baric, R.S., Lazear, H.M., Silva, A.M., 2017. Lack of durable cross-neutralizing antibodies against zika virus from dengue virus infection. Emerg. Infect. Dis. 23, 773-781.

Cordeiro, M.T., Brito, C.A., Pena, L.J., 2016. Results of a Zika virus (ZIKV) immunoglobulin M-specific diagnostic assay are highly correlated with detection of neutralizing anti-ZIKV antibodies in neonates with congenital disease. J. Infect. Dis. 214, 1897-1904.

Coura, J.R., Suárez-Mutis, M., Ladeia-Andrade, S., 2006. A new challenge for malaria control in Brazil: asymptomatic Plasmodium infection-a review. Memórias do Inst. Oswaldo Cruz 101, 229-237.

Dang, J., Tiwari, S.K., Lichinchi, G., Qin, Y., Patil, V.S., Eroshkin, A.M., Rana, T.M., 2016. Zika virus depletes neural progenitors in human cerebral organoids through activation of the innate immune receptor TLR3. Cell Stem Cell. 19, 258-265.

de Oliveira Dias, J.R., Ventura, C.V., Borba, P.D., de Paula Freitas, B., Pierroti, L.C., do Nascimento, A.P., de Moraes, N.S., Maia, M., Belfort Jr., R., 2017 Jan 2. Infants with congenital Zika syndrome and Ocular findings from Sao Paulo, Brazil: spread of infection. Retin. Cases Brief Rep. http://dx.doi.org/10.1097/ICB.0000000000000518. [Epub ahead of print].

de Paula Freitas, B., de Oliveira Dias, J.R., Prazeres, J., Sacramento, G.A., Ko, A.I., Maia, M., Belfort Jr., R., 2016. Ocular findings in infants with microcephaly associated with presumed Zika Virus congenital infection in Salvador, Brazil. JAMA. Ophthalmol [Epub ahead of print].

de Paula Freitas, B., Ko, A.I., Khouri, R., Mayoral, M., Henriques, D.F., Maia, M., Belfort Jr., R., 2017 Mara. Glaucoma and congenital Zika syndrome. Ophthalmology 124 (3), 407-408.

de Paula Freitas, B., Zin, A., Ko, A., Maia, M., Ventura, C.V., Belfort Jr., R., 2017b. Anterior-segment ocular findings and microphthalmia in congenital zika syndrome. Ophthalmology [Epub ahead of print].

Deckard, D.T., 2016. Male-to-male sexual transmission of Zika virus-Texas, January 2016. MMWR (Morb. Mortal. Wkly. Rep.) 65, 372-374.

Diallo, D., Sall, A.A., Diagne, C.T., Faye, O., Faye, O., Ba, Y., Hanley, K.A., Buenemann, M., Weaver, S.C., Diallo, M., 2011. Zika virus emergence in mosquitoes in southeastern Senegal. PLoS One 9, e109442.

Dick, G.W., Kitchen, S.F., Haddow, A.J., 1952. Zika virus. I. Isolations and serological specificity. Trans. R. Soc. Trop. Med. Hyg. 46, 509-520.

Duffy, M.R., Chen, T.H., Hancock, W.T., Powers, A.M., Kool, J.L., Lanciotti, R.S., Pretrick, M., Marfel, M., Holzbauer, S., Dubray, C., Guillaumot, L., Griggs, A., Bel, M., Lambert, A.J., Laven, J., Kosoy, O., Panella, A., Biggerstaff, B.J., Fischer, M., Hayes, E.B., 2009. Zika virus outbreak on Yap island, Federated States OF Micronesia. N. Engl. J. Med. 360, 2536-2543.

Duong, V., Lambrechts, L., Paul, R.E., Ly, S., Lay, R.S., Long, K.C., Huy, R., Tarantola, A., Scott, T.W., Sakuntabhai, A., Buchy, P., 2015. Asymptomatic humans transmit dengue virus to mosquitoes. Proc. Natl. Acad. Sci. U. S. A. 112, 14688-14693.

Dupont-Rouzeyrol, M., O'Connor, O., Calvez, E., Daures, M., John, M., Grangeon, J.P., Gourinat, A.C., 2015. Co-infection with Zika and dengue viruses in 2 patients, New Caledonia, 2014. Emerg. Infect. Dis. 21 (2), 381-382.

Dupont-Rouzeyrol, M., Biron, A., O'Connor, O., Huguon, E., Descloux, E., 2016. Infectious Zika viral particles in breastmilk. Lancet 387, 1051.

D'Ortenzio, E., Matheron, S., Yazdanpanah, Y., de Lamballerie, X., Hubert, B., Piorkowski, G., Maquart, M., Descamps, D., Damond, F., Leparc-Goffart, I., 2016. Evidence of sexual transmission of zika virus. 2016. N. Engl. J. Med. 374, 2195-2198.

Epelboin, Y., Talaga, S., Epelboin, L., Dusfour, I., 2017 Nov 16. Zika virus: an updated review of competent or naturally infected mosquitoes. PLoS Negl Trop Dis. 11 (11), e0005933.

European Centre for Disease Prevention and Control (ECDC), 2017a. Zika transmission. Available at:. Current Zika transmission. https://ecdc.europa.eu/en/zika-virusinfection/threats-and-outbreaks/zika-transmission (Accessed on March 31, 2018).

European Centre for Disease Prevention and Control (ECDC), 2017b. Zika Virus Transmission - List of Countries: ECDC Adaptation of WHO's Zika Virus Country Classification Scheme. Available at:. https://ecdc.europa.eu/en/publications-data/ current-zika-virus-transmission-list-countries-ecdc-adaptation-whos-zika-virus (Accessed on March 24, 2018).

Fagbami, A.H., 1979 Oct. Zika virus infections in Nigeria: virological and seroepidemiological investigations in Oyo State. J. Hyg. (Lond) 83 (2), 213-219.

Favoretto, S., Araújo, D., Oliveira, D., Duarte, N., Mesquita, F., Zanotto, P., Durigon, E., 2016. First detection of Zika virus in neotropical primates in Brazil: a possible new reservoir. bioRxiv.

Faye, O., Freire, C.C.M., Iamarino, A., Faye, O., de Oliveira, J.V.C., Diallo, M., Zanotto, P.M.A., Sall, A.A., 2014 Jan 9. Molecular evolution of zika virus during its emergence in the $20^{\text {th }}$ century. PLoS Negl. Trop. Dis. 8 (1), e2636.

Fernandez, M.P., Parra Saad, E., Ospina Martinez, M., Corchuelo, S., Mercado Reyes, M., Herrera, M.J., Parra Saavedra, M., Rico, A., Fernandez, A.M., Lee, R.K., Ventura, C.V., Berrocal, A.M., Dubovy, S.R., 2017. Ocular histopathologic features of congenital Zika syndrome. JAMA Ophthalmology [Epub ahead of print].

Food and Drug Administration, 2016. Zika Virus Emergency Use Authorization. US Department of Health and Human Services, Food and Drug Administration, Silver Spring, MD Available at: http://sci-hub.hk/http://www.fda.gov/MedicalDevices/ Safety/EmergencySituations/ucm161496.htm (Accessed on March 31, 2018).

Foy, B.D., Kobylinski, K.C., Chilson Foy, J.L., Blitvitch, B.J., Travassos da Rosa, A., Haddow, A.D., Lanciotti, R.S., Tesh, R.B., 2011. Probable non-vector-borne transmission of Zika virus, Colorado, USA. Emerg. Infect. Dis. 17, 880-882.

Frank, C., Cadar, D., Schlaphof, A., Neddersen, N., Günther, S., Schimidt-Chanasit, J., Tappe, D., 2016. Sexual transmission of zika virus in Germany, April 2016. 2016. Euro Surveill. 21.

França, G.V., Schuler-Faccini, L., Oliveira, W.K., Henriques, C.M., Carmo, E.H., Pedi, V.D., Nunes, M.L., Castro, M.C., Serruya, S., Silveira, M.F., Barros, F.C., Victora, C.G., 2016 Congenital Zika virus syndrome in Brazil: a case series of the first 1501 live births with complete investigation. Lancet 388, 891-897.

Fung, J.C., Tilton, R.C., 1985. TORCH serologies and specific IgM antibody determination in Acquired and congenital infections. Ann. Clin. Lab. Sci. 15, 204-211.

Furtado, J.M., Espósito, D.L., Klein, T.M., Teixeira-Pinto, T., da Fonseca, B.A., 2016. Uveitis associated with Zika virus infection. N. Engl. J. Med. 375, 394-396.

Gake, B., Vernet, M.A., Leparc-Goffart, I., Drexler, J.F., Gould, E.A., Gallian, P., de Lamballerie, $\mathrm{X}, 2017$. Low seroprevalence of Zika virus in Cameroonian blood 
donors. Braz. J. Infect. Dis. 21, 481-483.

Gallian, P., Cabié, A., Richard, P., Paturel, L., Charrel, R.N., Pastorino, B., Leparc-Goffart, I., Tiberghien, P., de Lamballerie, X., 2017. Zika virus in asymptomatic blood donors in Martinique. Blood 129, 263-266.

Gardner, L.M., Chen, N., Sarkar, S., 2016. Global risk of Zika virus depends critically on vector status of Aedes albopictus. Lancet Infect. Dis. 16, 522-523.

Gardner, L., Chen, N., Sarkar, S., 2017. Vector status of Aedes species determines geographical risk of autochthonous Zika virus establishment. PLoS Neglected Trop. Dis. 11 e0005487.

Garg, S., Mets, M.B., Bearelly, S., Mets, R., 2009. Imaging of congenital toxoplasmosis macular scars with optical coherence tomography. Retina 29, 631-637.

Gasperi, G., Bellini, R., Malacrida, A.R., Crisanti, A., Dottori, M., Aksoy, S., 2014. A new threat looming over the Mediterranean basis: emergence of viral diseases transmitted by Aedes albopictus mosquitoes. PLoS Neglected Trop. Dis. 6, e1836.

Gatherer, D., Kohl, A., 2016. Zika virus: a previously slow pandemic spreads rapidly through the Americas. J. Gen. Virol. 97, 269-273.

Goldenberg, D., Goldstein, M., Loewenstein, A., Habot-Wilner, Z., 2013. Vitreal, retinal, and choroidal findings in active and scarred toxoplasmosis lesions: a prospective study by spectral-domain optical coherence tomography. Graefes Arch. Clin. Exp. Ophthalmol. 251, 2037-2045.

Gourinat, A.C., O'Connor, O., Calvez, E., Goarant, C., Dupont-Rouzeyrol, M., 2015. Detection of Zika virus in urine. Emerg. Infect. Dis. 21, 84-86.

Grard, G., Caron, M., Mombo, I.M., Nkoghe, D., Mboui Ondo, S., Jiolle, D., Fontenille, D., Paupy, C., Leroy, E.M., 2014. Zika virus in Gabon (Central Africa)-2007: a new threat from Aedes albopictus? PLoS Neglected Trop. Dis. 8, e2681.

Gratz, N.G., 2004. Critical review of the vector status of Aedes albopictus. Med. Vet. Entomol. 18, 215-227.

Gubler, D.J., 2002. Epidemic dengue/dengue hemorrhagic fever as a public health, social and economic problem in the 21st century. Trends Microbiol. 10, 100-103.

Haddow, A.D., Schuch, A.J., Yasuda, C.Y., Kasper, M.R., Heang, V., Huy, R., Guzman, H., Tesh, R.B., Weaver, S.C., 2012. Genetic characterization of zika virus strains: geographic expansion of the Asian lineage. PLoS Neglected Trop. Dis. 6, e1477.

Hamer, D.H., Chen, L.H., 2014. Chikungunya: establishing a new home in the Western hemisphere. Ann. Intern. Med. 161, 827-828.

Harrower, J., Kiedrzynski, T., Baker, S., Upton, A., Rahnama, F., Sherwood, J., Huang, Q.S., Todd, A., Pulford, D., 2016. Sexual transmission of Zika virus and persistence in semen, New Zealand, 2016. Emerg. Infect. Dis. 22, 1855-1857.

Honein, M.A., Dawson, A.L., Petersen, E.E., Jones, A.M., Lee, E.H., Yazdy, M.M., Ahmad, N., Macdonald, J., Evert, N., Bingham, A., Ellington, S.R., Shapiro-Mendoza, C.K., Oduyebo, T., Fine, A.D., Brown, C.M., Sommer, J.N., Gupta, J., Cavicchia, P., Slavinski, S., White, J.L., Owen, S.M., Petersen, L.R., Boyle, C., Meaney-Delman, D., Jamieson, D.J., US Zika Pregnancy Registry Collaboration, 2017. Birth defects among fetuses and infants of US women wilth evidence of possible zika virus infefcion during pregnancy. J. Am. Med. Assoc. 317, 59-68.

Intergrowth-21st Fetal, 2017. Preterm and Newborn Applications. Available at:. https:// intergrowth21.tghn.org/fetal-preterm-and-newborn-applications/ (Accessed on April $28,2018)$.

Ioos, S., Mallet, H.P., Leparc Goffart, I, Gauthier, V., Cardoso, T., Herida, M., 2014. Current Zika virus epidemiology and recent epidemics. Med. Maladies Infect. 44, 302-307.

Jan, C., Languillat, G., Renaudet, J., Robin, Y., 1978. A serological survey of arboviruses in Gabon. Bull Soc Pathol Exot Filiales 71, 140-146.

Johansson, M.A., Mier-y-Teran-Romero, L., Reefhuis, J., Gilboa, S.M., Hills, S.L., 2016. Zika and the risk of microcephaly. N. Engl. J. Med. 375, 1-4.

Kodati, S., Palmore, T.N., Spellman, F.A., Cunningham, D., Weistrop, B., Sen, H.N., 2016. Bilateral posterior uveitis associated with Zika virus infection. Lancet 389, 125-126.

Kostyuchenko, V.A., Lim, E.X., Zhang, S., Fibriansah, G., Ng, T.S., Ooi, J.S., Shi, J., Lok, S.M., 2016. Structure of the thermally stable Zika virus. Nature 533, 425-428.

Kraemer, M.U., Sinka, M.E., Duda, K.A., Mylne, A.Q., Shearer, F.M., Barker, C.M., Moore, C.G., Carvalho, R.G., Coelho, G.E., Van Bortel, W., Hendrickx, G., Schaffner, F., Elyazar, I.R., Teng, H.J., Brady, O.J., Messina, J.P., Pigott, D.M., Scott, T.W., Smith, D.L., Wint, G.R., Golding, N., Hay, S.I., 2015. The global distribution of the arbovirus vectors Aedes aegypti and Ae. albopictus. Elife. 4 e08347.

Krow-Lucal, E.R., Biggerstaff, B.J., Staples, J.E., 2017. Estimated incubation period for zika virus disease. Emerg. Infect. Dis. 23, 841-845.

Kuno, G., Chang, G.J., 2007. Full-length sequencing and genomic characterization of Bagazam Kedougou, and Zika viruses. Arch Viol 152, 687-696.

Lanciotti, R.S., Kosoy, O.L., Laven, J.J., Velez, J.O., Lambert, A.J., Johnson, A.J., Stanfield, S.M., Duffy, M.R., 2008. Genetic and serologic properties of Zika virus associated with an epidemic, Yap State, Micronesia, 2007. Emerg Infecy Dis 14, 1232-1239.

Lanciotti, R.S., Lambert, A.J., Holodniy, M., Saavedra, S., 2016. del Carmen Castillo Signor, L. Emerg. Infect. Dis. 22, 933-955.

Leder, K., Grobusch, M.P., Gautret, P., Chen, L.H., Kuhn, S., Lim, P.L., Yates, J., McCarthy, A.E., Rothe, C., Kato, Y., Bottieau, E., Huber, K., Schwartz, E., Stauffer, W., Malvy, D., Shaw, M.T.M., Rapp, C., Blumberg, L., Jensenius, M., van Genderen, P.J.J., Hamer, D.H., GeoSentinel Surveillance Network, 2017. Zika beyond the Americas: travelers as sentinels of zika virus transmission. A GeoSentinel analysis, 2012 to 2016. PLoS One 12 e0185689.

Lindsey, N.P., Lehman, J.A., Staples, J.E., Fischer, M., 2015. West Nile virus and other nationally notifiable arboviral diseases - United States, 2014. MMWR Morb. Mortal. Wkly. Rep. 64, 929-934.

Macnamara, F.N., 1952. Annual Report. Virus Research Institute, Nigeria, pp. 1951-1952 for.

Mani, R.S., 2016. Microcephaly not a reliable indicator of congenital Zika virus syndrome in infants. Natl. Med. J. India 29, 339-340.
Marchette, N.J., Garcia, R., Rudnick, A., 1969. Isolation of Zika virus from Aedes aegypti mosquitoes in Malaysia. Am. J. Trop. Med. Hyg. 18, 411-415.

Marcondes, C.B., Ximenes, M., de, F., 2016. Zika virus in Brazil and the danger of infestation by Aedes (Stegomyia) mosquitoes. Rev. Soc. Bras. Med. Trop. 49, 4-10.

Martin, D.A., Muth, D.A., Brown, T., Johnson, A.J., Karabatsos, N., Roehrig, J.T., 2000. Standardization of immunoglobulin M capture enzyme-linked immunosorbent assays for routine diagnosis of arboviral infections. J. Clin. Microbiol. 38, 1823-1826.

Martines, R.B., Bhatnagar, J., de Oliveira Ramos, A.M., Davi, H.P., Iglezias, S.D., Kanamura, C.T., Keating, M.K., Hale, G., Silva-Flannery, L., Muehlenbachs, A., Ritter, J., Gary, J., Rollin, D., Goldsmith, C.S., Reagan-Steiner, S., Ermias, Y., Suzuki, T., Luz, K.G., de Oliveira, W.K., Lanciotti, R., Lambert, A., Shieh, W.J., Zaki, S.R., 2016. Pathology of congenital Zika syndrome in Brazil: a case series. Lancet 388, 898-904.

McCrae, A.W., Kirya, B.G., 1982. Yellow fever and Zika virus epizootics and enzootics in Uganda. Trans. R. Soc. Trop. Med. Hyg. 76, 552-562.

Medlock, J.M., Leach, S.A., 2015. Effect of climate change on vector-borne disease risk in the UK. Lancet Infect. Dis. 15, 721-730.

Medlock, J.M., Hansford, K.M., Schaffner, F., Versteirt, V., Hendrickx, G., Zeller, H., Van Bortel, W., 2012. Vector Borne Zoonotic Dis. A Review of the Invasive Mosquitoes in Europe: Ecology, Public Health Risks, and Control Options, vol. 12. pp. 435-447.

Miner, J.J., Sene, A., Richner, J.M., Smith, A.M., Santeford, A., Ban, N., Weger-Lucarelli, J., Manzella, F., Rückert, C., Govero, J., Noguchi, K.K., Ebel, G.D., Diamonds, M.S., Apte, R.S., 2016. Zika virus infection in mice causes panuveitis with shedding of virus in tears. Cell Rep. 16, 3208-3218.

Ministério da Saúde do Brasil, 2016b. I. nforme Epidemiológico No. 47 - SEMANA Epidemiológica (SE) 40/2016 (02/10/2016 a 08/10/2016) Monitoramento Dos Casos De Microcefalia No Brasil.

Ministério da Saúde do Brasil, 2017. Monitoramento integrado de alterações no crescimento e desenvolvimento relacionadas à infecção pelo vírus Zika e outras etiologias infecciosas, até a Semana Epidemiológica 20/2017. Boletim Epidemiológico 48 (19), 2017.

Ministério da Saúde do Brasil, Boletim, 2016a. Microcefalia: 1.749 Casos Confirmados No Brasil.

Miranda 2nd, H.A., Costa, M.C., Frazão, M.A., Simão, N., Franchischini, S., Moshfeghi, D.M., 2016. Expanded spectrum of congenital ocular findings in microcephaly with presumed Zika infection. Ophthalmology 123, 1788-1794.

Mladinich, M.C., Scwedes, J., Mackow, E.R., 2017. Zika virus persistently infects and is basolaterally released from primary human brain microvascular endothelial cells. 2017. mBio 8.

Mlakar, J., Korva, M., Tul, N., Popović, M., Poljšak-Prijatelj, M., Mraz, J., Kolenc, M., Resman Rus, K., Vesnaver Vipotnik, T., Fabjan Vodušek, V., Vizjak, A., Pižem, J., Petrovec, M., Avšič Županc, T., 2016. Zika virus associated with microcephaly. N. Engl. J. Med. 374, 951-958.

Monlun, E., Zeller, H., Le Guenno, B., Traoré-Lamizana, M., Hervy, J.P., Adam, F., Ferrara, L., Fontenille, D., Sylla, R., Mondo, M., 1993. Surveillance of the circulation of arbovirus of medical interest in the region of eastern Senegal. Bull. Soc. Pathol. Exot. 86, 21-28.

Moore, C.A., Staples, J.E., Dobyns, W.B., Pessoa, A., Ventura, C.V., Fonseca, E.B., Ribeiro, E.M., Ventura, L.O., Neto, N.N., Arena, J.F., Rasmussen, S.A., 2017. Characterizing the pattern of anomalies in congenital Zika syndrome for pediatric clinicians. J.A.M.A. Pediatr 171, 288-295.

Moreira-Soto, A., Carneiro, I.O., Fischer, C., Feldmann, M., Kümmerer, B.M., Silva, N.S. Santos, U.G., Souza, B.F.C.D., Liborio, F.A., Valença-Montenegro, M.M., Laroque, P.O., da Fontoura, F.R., Oliveira, A.V.D., Drosten, C., de Lamballerie, X., Franke, C.R., Drexler, J.F., 2018 Jan 31. Limited evidence for infection of urban and peri-urban nonhuman primates with zika and chikungunya viruses in Brazil. mSphere 3 (1) pii: e00523-17.

Morris, G., Barichello, T., Stubbs, B., Köhler, C.A., Carvalho, A.F., Maes, M., 2017. Zika virus as an emerging neuropathogen: mechanisms of neurovirulence and neuro-immune interactions. 2017. Mol. Neurobiol [Epub ahead of print].

Motta, I.J., Spencer, B.R., Cordeiro da Silva, S.G., Arruda, M.B., Dobbin, J.A., Gonzaga, Y.B., Arcuri, I.P., Tavares, R.C., Atta, E.H., Fernandes, R.F., Costa, D.A., Ribeiro, L.J., Limonte, F., Higa, L.M., Voloch, C.M., Brindeiro, R.M., Tanuri, A., Ferreira Jr., O.C., 2016. Evidence for transmission of Zika virus by platelet transfusion. N. Engl. J. Med. 375, 1101-1103.

Mousson, L., Dauga, C., Garrigues, T., Schaffner, F., Vazeille, M., Failloux, A.B., 2005 Phylogeography of Aedes (Stegomyia) aegypti (L.) and Aedes (Stegomyia) albopictus (Skuse) (Diptera: Culicidae) based on mitochondrial DNA variations. Genet. Res. 86, $1-11$.

Musso, D., 2015. Zika virus transmission from French Polynesia to Brazil. Emerg. Infect. Dis. 21, 1887.

Musso, D., Gubler, D.J., 2016. Zika virus. Clin. Microbiol. Rev. 29, 487-524.

Mysorekar, I.U., Diamond, M.S., 2016. Modeling Zika virus infection in pregnancy. N. Engl. J. Med. 375, 481-484.

Nogueira, M.L., Estofolete, C.F., Terzian, A.C., Mascarin do Vale, E.P., da Silva, R.C., da Silva, R.F., Ramalho, H.J., Fernandes Charpiot, I.M., Vasilakis, N., Abbud-Filho, M., 2017. Zika virus infection and solid organ transplantation: a new challenge. Am. J. Transplant. 17, 791-795.

Noronha, L.D., Zanluca, C., Azevedo, M.L.V., Luz, K.G., Santos, C.N., 2016. Zika virus damages the human placental barrier and presents marked fetal neurotropism. Mem. Inst. Oswaldo Cruz 111, 287-293.

Nunes, M.R., Faria, N.R., de Vasconcelos, J.M., Golding, N., Kraemer, M.U., de Oliveira, L.F., Azevedo Rdo, S., da Silva, D.E., da Silva, E.V., da Silva, S.P., Carvalho, V.L., Coelho, G.E., Cruz, A.C., Rodrigues, S.G., Vianez Jr., J.L., Nunes, B.T., Cardoso, J.F., Tesh, R.B., Hay, S.I., Pybus, O.G., Vasconcelos, P.F., 2015 Apr 30. Emergence and potential for spread of Chikungunya virus in Brazil. BMC Med. 13, 102.

Oehler, E., Watrin, L., Larre, P., Leparc-Goffart, I., Lastère, S., Valour, F., Baudouin, L., 
Mallet, H., Musso, D., Ghawche, F., 2014. Zika vírus infection complicated by Guillain-Barré syndrome-case report. French Polynesia December 2013. Euro Surveill. 19.

Olson, J.G., Ksiazek, T.G., triwibowo, Suhandiman, 1981. Zika virus, a cause of fever in Central Java, Indonesia. Trans. R. Soc. Trop. Med. Hyg. 75, 389-393.

Olson, J.G., Ksiazek, T.G., Gubler, D.J., Lubis, S.I., Simanjuntak, G., Lee, V.H., Nalim, S., Juslis, K., See, R., 1983. A survey for arboviral antibodies in sera of humans and animals in Lombok, Republic of Indonesia. Ann. Trop. Med. Parasitol. 77, 131-137.

Paixão, E.S., Teixeira, M.G., Rodrigues, L.C., 2018. Zika, chikungunya and dengue: the causes and threats of new and re-emerging arboviral diseases. BMJ Glob Health. 3 e000530.

Pan American Health Organization/World Health Organization, 2016. Zika Vírus Infection: Step by Step Guide on Risk Communications and Community Engagement. Availabe at:. http://www.paho.org/hq/index.php?option = com_docman\&task = doc_view\&gid $=33051$ \&Itemid $=270 \& l a n g=e m$ (Accessed April 1, 2018).

Parke 3rd, D.W., Almeida, D.R., Albini, T.A., Ventura, C.V., Berrocal, A.M., Mittra, R.A., 2016. Serologically confirmed Zika-related unilateral acute maculopathy in an adult. Ophthalmology 123, 2432-2433.

Petersen, L.R., Jamieson, D.J., Powers, A.M., Honein, M.A., 2016a. Zika virus. N. Engl. J. Med. 374, 1552-1563.

Petersen, E.E., Polen, K.N.D., Meaney-Delman, D., Ellington, S.R., Oduyebo, T., Cohn, A., Oster, A.M., Russell, K., Kawwass, J.F., Karwowski, M.P., Powers, A.M., Bertolli, J., Brooks, J.T., Kissin, D., Villanueva, J., Muñoz-Jordan, J., Kuehnert, M., Olson, C.K., Honein, M.A., Rivera, M., Jamieson, D.J., Rasmussen, S.A., 2016b. Update: interim guidelines for health care providers caring for pregnant women and women of reproductive age with possible Zika virus exposure-United States, 2016. MMWR Morb. Mortal. Wkly. Rep. 65, 315-322.

Pinto Junior, V.L., Luz, K., Parreira, R., Ferrinho, P., 2015. Zika Virus: a review for clinicians. Acta Med. Port. 28, 760-765.

Poland, J.D., Calisher, C.H., Monath, T.P., Downs, W.G., Murphy, K., 1981. Persistence of neutralizing antibody 30-35 years after immunization with 17D yellow fever vaccine. Bull. World Health Organ. 59, 895-900.

Rabe, I.B., Staples, J.E., Villanueva, J., Hummel, K.B., Johnson, J.A., Rose, L., MTS, Hills S., Wasley, A., Fischer, M., Powers, A.M., 2016. Interim guidance for interpretation of zika virus antibody test results. MMWR Morb. Mortal. Wkly. Rep. 65, 543-546.

Rajah, M.M., Pardy, R.D., Condotta, S.A., Richer, M.J., Sagan, S.M., 2016. Zika virus: emergence, phylogenetics, challenges, and opportunities. 2016. ACS Infect. Dis. 2, 763-772.

Retalack, H., Di Lullo, E., Arias, C., Knopp, K.A., Laurie, M.T., Sandoval-Espinosa, C., Mancia Leon, W.R., Krencik, R., Ullian, E.M., Spatazza, J., Pollen, A.A., MandelBrehm, C., Nowakowski, T.J., Kriegstein, A.R., DeRisi, J.L., 2016. Zika virus cell tropism in the developing human brain and inhibition by azithromycin. Proc. Natl. Acad. Sci. U.S.A. 113 14480-14413.

Reuters, 2016. Brazil reports Zika Infection from Blood Transfusions. Available at: (Accessed March 24, 2018). http://www.reuters.com/article/us-health-zika-brazilblood-idUSKCNOVD22N.

Rigau-Pérez, J.G., Clark, G.G., Gubler, D.J., Reiter, P., Sanders, E.J., Vorndam, A.V., 1998. Dengue and dengue haemorrhagic fever. Lancet 352, 971-977.

Ritter, J.M., Martines, R.B., Zaki, S.R., 2017. Zika virus: pathology from the pandemic. Arch. Pathol. Lab Med. 141, 49-59.

Roach, T., Alcendor, D.J., 2017. Zika virus infection of cellular components of the bloodretinal barriers: implications for viral associated congenital ocular disease. J. Neuroinflammation 14, 43.

Robbiani, D.F., Bozzacco, L., Keeffe, J.R., Khouri, R., Olsen, P.C., Gazumyan, A., SchaeferBabajew, D., Avila-Rios, S., Nogueira, L., Patel, R., Azzopardi, S.A., Uhl, L.F.K., Saeed, M., Sevilla-Reyes, E.E., Agudelo, M., Yao, K., Golijanin, J., Gristick, H.B., Lee, Y.E., Hurley, A., Caskey, M., Pai, J., Oliveira, T., Wunder Jr., E.A., Sacramento, G., Nery Jr., N., Orge, C., Costa, F., Reis, M.G., Thomas, N.M., Eisenreich, T., Weinberger, D.M., Almeida, A.R.P., West Jr., A.P., Rice, C.M., Bjorkman, P.J., Reyes-Teran, G., Ko, A.I., MacDonald, M.E., Nussenzweig, M.C., 2017. Recurrent potent human neutralizing antibodies to zika virus in Brazil and Mexico. Cell 169, 597-609.

Robin, Y., Mouchet, J., 1978. Serological and entomological study on yellow fever in Sierra Leone. Bull Soc Pathol Exot Filiales 68, 249-258.

Rochlin, I., Ninivaggi, D.V., Hutchinson, M.L., Farajollahi, A., 2013. Climate change and range expansion of the Asian tiger mosquito (Aedes albopictus) in Northeastern USA: implications for public health practitioners. PLoS One 8, e60874.

Rosenberg, A.Z., Yu, W., Hill, D.A., Reyes, C.A., Schwartz, D.A., 2016. Placental Pathology of Zika virus: viral infection of the placenta induces villous stromal macrophage (Hofbauer cell) proliferation and hyperplasia. Arch. Pathol. Lab Med. 141, 43-48.

Roth, A., Mercier, A., Lepers, C., Hoy, D., Duituturaga, S., Benyon, E., Guillaumot, L., Souarès, Y., 2014. Concurrent outbreaks of dengue, chikungunya and Zika virus infections - an unprecedented epidemic wave of mosquito-borne viruses in the Pacific 2012-2014. Euro Surveill. 16.

Saba Villarroel, P.M., Nurtop, E., Pastorino, B., Roca, Y., Drexler, J.F., Gallian, P., Jaenisch, T., Leparc-Goffart, I., Priet, S., Ninove, L., de Lamballerie, X., 2018. Zika virus epidemiology in Bolivia: a seroprevalence study in volunteer blood donors. PLoS Neglected Trop. Dis. 12 e0006239.

Saiz, J.C., Martín-Acebes, M.A., Bueno-Marí, R., Salomón, O.D., Villamil-Jiménez, L.C., Heukelbach, J., Alencar, C.H., Armstrong, P.K., Ortiga-Carvalho, T.M., MendezOtero, R., Rosado-de-Castro, P.H., Pimentel-Coelho, P.M., 2017. Zika virus: what have we learnt since the start of the recent epidemic? Front. Microbiol. 8, 1554.

Salam, A.P., Horby, P.W., 2017. The breadth of viruses in human semen. Emerg. Infect. Dis. 23, 1922-1924.

Saluzzo, J.F., Gonzalez, J.P., Hervé, J.P., Georges, A.J., 1981. Serological survey for the prevalence of certain arboviruses in the human population of the south-east area of
Central African Republic. Bull Soc Pathol Exot Filiales 74, 490-499.

Salvo, M.A., Kingstad-Bakke, B., Salas-Quinchucua, C., Camacho, E., Osorio, J.E., 2018. Zika virus like particles elicit protective antibodies in mice. PLoS Neglected Trop. Dis. 12 e0006210.

Sampathkumar, P., Sanchez, J.L., 2016. Zika virus in the Americas: a review for clinicians. Mayo Clin. Proc. 91, 514-521.

Sapparapu, G., Fernandez, E., Kose, N., Cao, B., Fox, J.M., Bombardi, R.G., Zhao, H., Nelson, C.A., Bryan, A.L., Barnes, T., Davidson, E., Mysorekar, I.U., Fremont, D.H., Doranz, B.J., Diamond, M.S., Crowe, J.E., 2016. Neutralizing human antibodies prevent Zika virus replication and fetal disease in mice. Nature 540, 443-447.

Schaffner, F., Medlock, J.M., Van Bortel, W., 2013. Public Health Significance of Invasive Mosquitoes in Europe, vol. 19. Clinical microbiology and infection: the official publication of the European Society of Clinical Microbiology and Infectious Diseases, pp. 685-692.

Schuler-Faccini, L., Ribeiro, E.M., Feitosa, I.M., Horovitz, D.D., Cavalcanti, D.P., Pessoa, A., Doriqui, M.J., Neri, J.I., Neto, J.M., Wanderley, H.Y., Cernach, M., El-Husny, A.S., Pone, M.V., Serao, C.L., Sanseverino, M.T., 2015. Brazilian medical genetics society-zika embryopathy task force. 2016. Possible association between zika virus infection and microcephaly - Brazil. MMWR Morb. Mortal. Wkly. Rep. 65, 59-62.

Schwartz, D.A., 2017. Autopsy and postmortem studies are concordant: pathology of zika virus infection is neurotropic in fetuses and infants with microcephaly following transplacental transmission. Arch. Pathol. Lab Med. 141, 68-72.

Secretaria de Estado de Saúde do Estado de São Paulo, 2016. Distribuição dos Casos Notificados e Confirmados de Febre pelo Vírus Zika, por mês de início de sintomas. Estado de São Paulo.

Sheridan, M.A., Yunusov, D., Balaraman, V., Alexenko, A.P., Yabe, S., Verjovski-Almeida, S., Schust, D.J., Franz, A.W., Sadovsky, Y., Ezashi, T., Roberts, R.M., 2017. Vulnerability of primitive human placental trophoblast to Zika virus. 2017. Proc. Natl. Acad. Sci. U. S. A. 114, E1587-E1596.

Simonin, Y., van Riel, D., Can de Perre, P., Rockx, B., Salinas, S., 2017. Differential virulence between Asian and african lineages of zika virus. PLoS Neglected Trop. Dis. 21 e0005821.

Singh, P.K., Guest, J.M., Kanwar, M., Boss, J., Gao, N., Juzych, M.S., Abrams, G.W., Yu, F.S., Kumar, A., 2017. Zika virus infects cells lining the blood-retinal barrier and causes chorioretinal atrophy in mouse eyes. JCI Insight 2, e92340.

Slavov, S.N., Otaguiri, K.K., Kashima, S., Covas, D.T., 2016. Overview of zika virus (ZIKV) infection in regards to the Brazilian epidemic. Braz. J. Med. Biol. Res. 49, e5420.

Slavov, S.N., Hesoanhol, M.R., Rodrigues, E.S., Levi, J.E., Ubiali, E.M.A., Covas, D.T., Kashima, S., 2017. Zika virus RNA detection in asymptomatic blood donors during an outbreak in the northeast region of São Paulo State, Brazil, 2016. 2017. Transfusion 57, 2897-2901.

Smithburn, K.C., 1952. Neutralizing antibodies against certain recently isolated viruses in the sera of human beings residing in East Africa. J. Immunol. 69, 223-234.

Subissi, L., Daudens-Vaysse, E., Cassadou, S., Ledrans, M., Bompard, P., Gustave, J., Aubry, M., Cao-Lormeau, V.M., Mallet, H.P., 2017. Revising rates of asymptomatic Zika virus infection based on sentinel surveillance data from French Overseas territories. Int. J. Infect. Dis. 65, 116-118.

Sun, L.L., Goodwin, T., Park, J.J., 2012. Optical coherence tomography changes in macular CMV retinitis. Digit. J. Ophthalmol. 18, 1-4.

Tang, H., Hammack, C., Ogden, S.C., Wen, Z., Qian, X., Li, Y., Yao, B., Shin, J., Zhang, F., Lee, E.M., Christian, K.M., Didier, R.A., Jin, P., Song, H., Ming, G.L., 2016. Zika virus infects human cortical neural progenitors and attenuates their growth. Cell Stem Cell. $18,587-590$.

Tognarelli, J., Ulloa, S., Villagra, E., Lagos, J., Aguayo, C., Fasce, R., Parra, B., Mora, J., Becerra, N., Lagos, N., Vera, L., Olivares, B., Vilches, M., Fernandéz, J., 2015. A report on the outbreak of zika virus on easter island, South Pacific, 2014. Arch. Virol. (161), 665-668.

Van den Berg, B., Walgaard, C., Drenthen, J., Fokke, C., Jacobs, B.C., van Doorn, P.A., 2014. Guillain-Barré syndrome: pathogenesis, diagnosis, treatment and prognosis. Nat. Rev. Neurol. 10, 469-482.

van den Pol, A.N., Mao, G., Yang, Y., Ornaghi, S., Davis, J.N., 2017. Zika virus targeting in the developing brain. J. Neurosci. 37, 2161-2175.

van der Linden, V., Filho, E.L., Lins, O.G., van der Linden, A., Aragão, M., de, F., BrainerLima, A.M., Cruz, D.D., Rocha, M.A., Sobral da Silva, P.F., Carvalho, M.D., do Amaral, F.J., Gomes, J.A., Ribeiro de Medeiros, I.C., Ventura, C.V., Ramos, R.C., 2016a. Congenital Zika syndrome with arthrogryposis: retrospective case series study. BMJ 354, i3899.

van der Linden, V., Pessoa, A., Dobyns, W., Barkovich, A.J., Júnior, H.V., Filho, E.L., Ribeiro, E.M., Leal, M.C., Coimbra, P.P., Aragão, M.F., Verçosa, I., Ventura, C., Ramos, R.C., Cruz, D.D., Cordeiro, M.T., Mota, V.M., Dott, M., Hillard, C., Moore, C.A., 2016b. Description of 13 infants born during October 2015-January 2016 with congenital Zika Virus infection without microcephaly at birth - Brazil. MMWR Morb. Mortal. Wkly. Rep. 65, 1343-1348.

Van Kerkhove, M.D., Reveiz, L., Souza, J.P., Jaenisch, T., Carson, G., Broutet, N., Working Group on ZIKV Harmonized Research, 2016. Harmonization of Zika vírus research protocols to address key public health concerns. 4, e911-e912.

Vega-Rua, A., Zouache, K., Caro, V., Diancourt, L., Delaunay, P., Grandadam, M., Failloux, A.B., et al., 2013. High efficiency of temperate Aedes albopictus to transmit chikungunya and dengue viruses in the Southeast of France. PLoS One 8 e59716.

Ventura, C.V., Ventura, L.O., Miller, M.T., Cronemberger, M.F., Dias, C.S., Dias, M.J., Gonzalez, C.H., Polati, M., Nakanami, C.R., Brandt, C.T., Kuczynski, E., Goldchmit, M., 2014. Teratogen exposure and congenital ocular abnormalities in Brazilian patients with Mobius sequence. Arq. Bras. Oftalmol. 77, 300-304.

Ventura, C.V., Maia, M., Bravo-Filho, V., Góis, A.L., Belfort Jr., R., 2016a. Zika virus in Brazil and macular atrophy in a child with microcephaly. Lancet 387, 228.

Ventura, C.V., Maia, M., Ventura, B.V., Linden, V.V., Araújo, E.B., Ramos, R.C., Rocha, 
M.A., Carvalho, M.D., Belfort Jr., R., Ventura, L.O., 2016b. Ophthalmological findings in infants with microcephaly and presumable intra-uterus Zika virus infection. Arq. Bras. Oftalmol. 79, 1-3.

Ventura, C.V., Maia, M., Travassos, S.B., Martins, T.T., Patriota, F., Nunes, M.E., Agra, C., Torres, V.L., van der Linden, V., Ramos, R.C., Rocha, M.Â., Silva, P.S., Ventura, L.O., Belfort Jr., R., 2016c. Risk factors associated with the ophthalmoscopic findings identified in infants with presumed Zika virus congenital infection. JAMA Ophthalmol 134, 912-918.

Ventura, C.V., Maia, M., Dias, N., Ventura, L.O., Belfort Jr., R., 2016d. Zika: neurological and ocular findings in infant without microcephaly. Lancet 387, 2502.

Ventura, C.V., Fernandez, M.P., Gonzalez, I.A., Rivera-Hernandez, D.M., Lopez-Alberola, R., Peinado, M., Floren, A.A., Rodriguez, P.A., Williams Jr., B.K., de la Vega Muns, G., Rodriguez, A.J., Negron, C., Fallas, B., Berrocal, A.M., 2016e. First travel-associated congenital Zika syndrome in the US: ocular and neurological findings in the absence of microcephaly. Ophthalmic Surg. Lasers Imaging Retina 47, 952-955.

Ventura, C.V., Ventura, L.O., Bravo-Filho, V., Martins, T.T., Berrocal, A.M., Gois, A.L, de Oliveira Dias, J.R., Araújo, L., Escarião, P., van der Linden, V., Belfort Jr., R., Maia, M., 2016f. Optical coherence tomography of retinal lesions in infants with congenital Zika syndrome. J.A.M.A. Ophthalmol. 134, 1420-1427.

Ventura, L.O., Ventura, C.V., Lawrence, L., van der Linden, V., van der Linden, A., Gois, A.L., Cavalcanti, M.M., Barros, E.A., Dias, N.C., Berrocal, A.M., Miller, M.T., 2017 Auga. Visual impairment in children with congenital Zika syndrome. J AAPOS 21 (4), 295-299 e2.

Ventura, L.O., Lawrence, L., Ventura, C.V., Dutton, G.N., Marinho, P., Ferro, P.F., Gois, A.L., Dias, N.C., Ventura, L., Moore, C.A., Hyvärinen, L., 2017b. Response to correction of refractive errors and hypoaccommodation in children with congenital Zika syndrome. J AAPOS [Epub ahead of print].

Verçosa, I., Carneiro, P., Verçosa, R., Girão, R., Ribeiro, E.M., Pessoa, A., Almeida, N.G., Verçosa, P., Tartarella, M.B., 2017. The visual system in infants with microcephaly related to presumed congenital Zika syndrome. J AAPOS 21, 300-304.

Vorou, R., 2016. Zika virus, vectors, reservoirs, amplifying hosts, and their potential to spread worldwide: what we know and what we should investigate urgently. Int. J. Infect. Dis. 48, 85-90.

Wang, L., Valderramos, S.G., Wu, A., Ouyang, S., Li, C., Brasil, P., Bonaldo, M., Coates, T. Nielsen-Saines, K., Jiang, T., Aliyari, R., Cheng, G., 2016. From mosquitos to humans: genetic evolution of zika virus. Cell Host Microbe 19, 561-565.

Weaver, S.C., Vasilakis, N., 2009. Molecular evolution of dengue viruses: contributions of phylogenetics to understanding the history and epidemiology of the preeminent arboviral disease. Infect. Genet. Evol. 9, 523-540.

Whitehead, S.S., Blaney, J.E., Durbin, A.P., Murphy, B.R., 2007. Prospects for a dengue virus vaccine. Nat. Rev. Microbiol. 5, 518-528.

WHO/Institut Pasteur/ISARIC/CONSISE Version 1.10, 24 January 2017. Standardized Protocol: Cross-sectional Seroprevalence Study of Zika Virus Infection in the General Population. Available at: v1.9.pdf. http://www.who.int/reproductivehealth/zika/ ZIKV-cross-sectional-protocol-v1.9.pdf Accessed on March 7, 2018.

Wolfe, N.D., Kilbourn, A.M., Karesh, W.B., Rahman, H.A., Bosi, E.J., Cropp, B.C., Andau, M., Spielman, A., Gubler, D.J., 2001. Sylvatic transmission of arboviruses among
Bornean orangutans. Am. J. Trop. Med. Hyg. 64, 310-316.

World Health Organization (WHO), 2016a. Zika Virus Vectors and Risk of Spread in the WHO European Region. [Web Page]; Available at:. http://www.euro.who.int/ data/assets/pdf_file/0007/304459/WEB-news_competence-of-Aedes-aegypti-andalbopictus-vector-species.pdf (Accessed March 22, 2018).

World Health Organization, 2016b. Zika Situation Report. Zika Virus, Microcephaly and Guillain-barré Syndrome. Available at:. . http://www.who.int/emergencies/zikavirus/situationreport/30-june-2016/en/ (Accessed March 3, 2018).

World Health Organization, 2016c. WHO Statement on the First Meeting of the International Health Regulations (2005) (IHR 2005) Emergency Committee on Zika Virus and Observed Increase in Neurological Disorders and Neonatal Malformations. WHO statement.

World Health Organization, 2016d. Surveillance for Zika Virus Infection, Microcephaly and Guillain- Barré Syndrome. Interim Guidance. Available at:. http://www.who. int/csr/resources/publications/zika/surveillance/en/ (Accessed March 22, 2018).

World Health Organization, 2017a. Information for Travelers Visiting Zika Affected Countries. Available at:. http://www.who.int/csr/disease/zika/information-fortravelers/en/ (Accessed on March 31, 2018).

World Health Organization, 2017b. Zika Situation Report. Available at:. . http://www. who.int/emergencies/zika-virus/situation-report/10-march-2017/en/ (Accessed on March 5, 2018).

World Health Organization, 2018. The History of Zika Virus. Available at:. http://www. who.int/emergencies/zika-virus/history/en/ (Accessed on March 22, 2018).

Yepez, J.B., Murati, F.A., Pettito, M., Peñaranda, C.F., de Yepez, J., Maestre, G., Arevalo, J.F., Johns Hopkins Hopkins Zika Zika Center, 2017. Ophthalmic manifestations of congenital Zika syndrome in Colombia and Venezuela. JAMA Ophthalmol 135, 440-445.

Zare Mehrjardi, M., 2017. Is Zika virus an emerging TORCH agent? An invited commentary. Virol. Res. Treat. $81178122 X 17708993$.

Zare Mehrjardi, M., Poretti, A., Keshavarz, E., 2017. Neuroimaging findings of Zika virus infection: emphasis of congenital versus acquired aspects. Jpn. J. Radiol. 35, 41-42.

Zhao, H., Fernandez, E., Dowd, K.A., Speer, S.D., Platt, D.J., Gorman, M.J., Govero, J., Nelson, C.A., Pierson, T.C., Diamond, M.S., Fremont, D.H., 2016. Structural basis of zika virus-specific antibody protection. Cell 166, 1016-1027.

Zhao, Z., Yang, M., Azar, S.R., Soong, L., Weaver, S.C., Sun, J., Chen, Y., Rossi, S.L., Cai, J., 2017. Viral retinopathy in experimental models of Zika infection. Invest. Ophthalmol. Vis. Sci. 58, 4355-4365.

Zhu, Z., Chan, J.F., Tee, K.M., Choi, G.K., Lau, S.K., Woo, P.C., Tse, H., Yuen, K.Y., 2016 Comparative genomic analysis of pre-epidemic and epidemic Zika virus strains for virological factors potentially associated with the rapidly expanding epidemic. Emerg. Microb. Infect. 16 (5), e22.

Zin, A.A., Tsui, I., Rossetto, J., Vasconcelos, Z., Adachi, K., Valderramos, S., Halai, U.A., Pone, M.V.D.S., Pone, S.M., Silveira Filho, J.C.B., Aibe, M.S., da Costa, A.C.C., Zin, O.A., Belfort Jr., R., Brasil, P., Nielsen-Saines, K., Moreira, M.E.L., 2017. Screening criteria for ophthalmic manifestations of congenital zika virus infection. JAMA Pediatr 171, 847-854. 